\title{
EL SISTEMA EDUCATIVO EN LA PROVINCIA DE LEÓN
}

\author{
Yolanda Fernández Santos \\ Economía Financiera y Contabilidad \\ Departamento de Dirección y Economía de la Empresa \\ Universidad de León \\ e-mail: yfers@unileon.es
}

1. Introducción - 2. El sistema educativo nacional - 3. Gasto público en educación: 3.1. Gasto público en enseñanza no universitaria, 3.2. Gasto público en enseñanza universitaria, 3.3. Becas y ayudas al estudio - 4. El sistema educativo en la provincia de León: 4.1. Enseñanzas de régimen general: 4.1.1. Alumnos matriculados en enseñanzas no universitarias, 4.1.2. Centros y unidades/grupos en enseñanza de régimen general - 5. Enseñanza universitaria - 6. Características educativas de la población - 7. Conclusiones - Referencias

\section{Introduc ción}

La Declaración Universal de Derechos Humanos de 10 de diciembre de 1948 considera a la educación como un derecho universal que tiene todo ser humano. En España, el artículo 27 de la Constitución Española de 1978 reconoce a la educación como un derecho fundamental de todos los ciudadanos, cuyo objetivo es el pleno desarrollo de la personalidad humana en el respeto a los principios democráticos de convivencia y a los derechos y libertades fundamentales.

Desde un punto de vista económico, la educación constituye uno de los pilares básicos sobre los que se asienta el desarrollo económico de una nación, ayudando a mejorar la competitividad tanto a nivel nacional como internacional.

Por otro lado y desde un punto de vista social, la educación sirve no sólo como un medio de acceso al mercado de trabajo, sino como un mecanismo de inclusión e integración social. Por ello, las políticas en esta materia en el ámbito comunitario y, especialmente, en el ámbito nacional y autonómico deben ir encaminadas a mejorar el capital humano y a reducir el fracaso escolar, es decir, mejorar los niveles educativos y capacidades de los ciudadanos.

El objetivo de este trabajo consiste en analizar la evolución del sistema educativo en la provincia de León a lo largo del periodo 1986-2012, teniendo en cuenta las limitaciones que se derivan de una falta de disponibilidad de datos. Para ello, se utiliza la información disponible en los Anuarios Estadísticos de Castilla y León y en las páginas webs del Instituto Nacional de Estadística, del Ministerio de Educación, Cultura y Deporte (MECD), y de la Universidad de León. Asimismo, se pretende efectuar, cuando los datos obtenidos lo permitan, un análisis comparativo de la situación de la educación en esta provincia con la que presenta la Comunidad Autónoma de Castilla y León, y España.

El estudio empírico sobre el Sistema Educativo en la provincia de León en el periodo indicado viene condicionado por varios factores: Primero, la reestructuración de las enseñanzas universi- 
tarias y no universitarias, como consecuencia de la existencia de frecuentes modificaciones normativas, hace que algunas de las enseñanzas analizadas no se estén impartiendo en la actualidad $^{1}$. No obstante, también se consideran estos estudios con el fin de analizar la evolución de ciertos indicadores a lo largo del tiempo en las distintas etapas educativas. Segundo, al considerar un periodo de tiempo tan amplio, surge el problema de la no disponibilidad de información homogénea de ciertas variables en las distintas bases de datos, en especial en aquéllas que hacen referencia al ámbito provincial, ya que, en muchos casos, se presentan datos agregados a nivel autonómico. Tercero, la falta de información de algunas de las variables en alguno de los años de estudio se soluciona calculando la media entre los valores que presenta dicha variable en el año anterior y posterior.

\section{E sistema educativo nacional}

Antes de pasar a analizar el sistema educativo en la provincia de León, conviene efectuar una breve referencia al marco normativo que lo regula, a las competencias que cada Administración tiene en esta materia y a las enseñanzas que ofrece el sistema educativo español en estos momentos.

El marco normativo en materia de educación a nivel nacional desde unos años antes de la instauración de la democracia en España viene marcado por las numerosas disposiciones legales aprobadas en estas cuatro últimas décadas, especialmente en la enseñanza no universitaria, con el propósito de adaptarse a las necesidades de cada momento. Esta normativa, tanto referida a la enseñanza universitaria como no universitaria, fundamentalmente, se concreta en las siguientes leyes y disposiciones:

- Ley 14/1970, de 4 de agosto, General de Educación y Financiamiento de la Reforma Educativa (LGE).

\footnotetext{
1 Tal es el caso de: la Enseñanza General Básica (EGB), el Bachillerato Unificado Polivalente (BUP), el Curso de Orientación Universitaria (COU), a nivel no universitario, y las titulaciones de Diplomado y Licenciado en proceso de extinción, a nivel universitario.
}

- Constitución Española de 1978.

- Ley Orgánica 5/1980, de la Jefatura del Estado, de 19 de Junio, por la que se regula el Estatuto de Centros Escolares (LOECE).

- Ley Orgánica 8/1985, de 3 de julio, Reguladora del Derecho de Educación (LODE).

- Ley Orgánica 11/1983, de 25 de agosto, de Reforma Universitaria (LRU).

- Ley Orgánica 1/1990, de 3 de octubre, de Ordenación General del Sistema Educativo (LOGSE) que deroga parte de la LGE de 1970.

- Ley Orgánica 9/1992, de 23 de Diciembre, de Transferencia de Competencias a Comunidades Autónomas que accedieron a la Autonomía por la Vía del Artículo 143 de la Constitución.

- Ley Orgánica 9/1995, de 20 de noviembre, de Participación, Evaluación y Gobierno de los Centros Docentes (LOPEG).

- Ley Orgánica 6/2001, de 21 de diciembre, de Universidades (LOU) que deroga la LRU.

- Ley Orgánica 10/2002, de 23 de diciembre, de Calidad de la Educación (LOCE).

- Ley Orgánica 2/2006, de 3 de mayo, de Educación (LOE) que deroga la LOGSE, la LOPEG, la LOCE y la parte en vigor de la LGE.

- Ley Orgánica 4/2007, de 12 de abril por la que se modifica la Ley Orgánica 6/2001, de 21de diciembre, de Universidades (LOMLOU).

- Ley Orgánica 8/2013, de 9 de diciembre, para la mejora de la calidad educativa (LOMCE) ${ }^{2}$.

De todas las disposiciones mencionadas anteriormente, únicamente afectan a la enseñanza universitaria la LRU, la LOU y la LOMLOU, el resto de normas regulan la enseñanza no universitaria. Como se puede comprobar, la relación de normas en materia de enseñanza no universitaria se caracteriza por ser numerosa y, a veces, con periodos breves de tiempo entre ellas, lo que no ha permitido llevar a cabo, en algunos casos, la aplicación completa de las nuevas fórmulas educativas aprobadas.

\footnotetext{
2 A la fecha de finalización de este trabajo todavía no ha entrado en vigor la LOMCE, por esta razón no ha sido considerada en los análisis realizados en este estudio, dado que los efectos de su aplicación no se pueden cuantificar.
} 
Inicialmente, las competencias en educación estaban en poder del Estado. Como consecuencia del proceso de descentralización llevado a cabo por el Gobierno Central, las competencias en Educación Superior comienzan a transferirse a la Comunidades Autónomas en los años 80, con la publicación de la Ley Orgánica 11/1983 de 25 de Agosto, de Reforma Universitaria (LRU). Esta reforma se centra principalmente en el sistema organizativo de las universidades y en su modernización científica, adquiriendo estas instituciones una mayor autonomía de gobierno, académica, financiera, administración de sus recursos, gestión del personal, establecimiento de procedimientos de admisión de alumnos, y diseño y propuesta de planes de estudios. En 1996, después de aprobarse el Real Decreto 907/1995, de 2 de junio, sobre traspaso de funciones y servicios de la Administración del Estado a la Comunidad Autónoma de Castilla y León en materia de Universidades, Castilla y León (CyL) recibe las competencias en materia de Educación Superior, perteneciendo al último grupo de Comunidades Autónomas $^{3}$ (CCAA) en adquirir esas funciones.

Posteriormente, el proceso de traspaso de las competencias de desarrollo legislativo y ejecución de la enseñanza en toda su extensión, niveles y grados, modalidades y especialidades, en materia de Educación no Superior, del Gobierno Central a las CCAA, se inicia a partir de la Ley Orgánica 9/1992, de 23 de diciembre, concretamente, en CyL después de la publicación de Real Decreto 1340/1999, de 31 de julio, sobre traspaso de funciones y servicios de la Administración del Estado a la Comunidad de Castilla y León en materia de enseñanza no universitaria. Todo ello, sin perjuicio de que el Estado se reserve las facultades para ejercer la Alta Inspección educativa, cuya función es comprobar el cumplimiento de los requisitos comunes establecidos por el mismo en materia de educación en todo el territorio nacional.

El modelo descentralizado de administración educativa actual contribuye a que las competencias en materia de educación se compartan esencialmente entre el Estado y las CCAA, si

3 Otras CCAA que recibieron las competencias en educación de la Administración Central son: Aragón, Castilla-La Mancha, Cantabria, La Rioja e Islas Baleares. bien pueden intervenir, en menor medida, la Administración Local y los centros docentes. Las competencias del Estado son principalmente normativas, aunque también cuenta con competencias de tipo ejecutivo. A las CCAA les corresponden competencias normativas para el desarrollo de las normas estatales básicas y la regulación de los elementos 0 aspectos no básicos del sistema educativo, así como las competencias ejecutivo-administrativas, excepto aquéllas reservadas al Estado. Los Ayuntamientos juegan un papel importante en la provisión de terreno para la construcción de centros públicos de Educación Infantil y Primaria, y en su conservación, reparación, vigilancia y gastos de mantenimiento. Finalmente, los centros escolares poseen autonomía para la gestión organizativa, pedagógica y económica (ver Cuadro 1).

En definitiva, el sistema educativo de la Comunidad de CyL depende en su mayoría de la Administración Autonómica, excepto en aquellas funciones reservadas a la Administración Central, cuyo objetivo es mantener cierta homogeneidad en el sistema educativo a nivel nacional. 


\section{Cuadro 1}

\section{Distribución de competencias en educación}

\begin{tabular}{|c|c|c|}
\hline & Competencias & Estructura administrativa \\
\hline $\begin{array}{l}\frac{0}{8} \\
\frac{\pi}{4} \\
\text { ú }\end{array}$ & $\begin{array}{l}\text { Ordenación general del sistema educativo, requisitos mínimos de los } \\
\text { centros, enseñanzas mínimas, cooperación internacional en materia } \\
\text { de enseñanza, fomento y coordinación general de la investigación y } \\
\text { regulación de los títulos académicos y profesionales. Alta inspección, } \\
\text { evaluaciones generales de diagnóstico de carácter estatal, política de } \\
\text { ayudas al estudio, titularidad y administración de los centros públicos } \\
\text { en el extranjero, régimen jurídico de los centros extranjeros en } \\
\text { España, estadística educativa para fines estatales, etc. }\end{array}$ & $\begin{array}{l}\text { Servicios centrales del Ministerio de } \\
\text { Educación, Cultura y Deporte } \\
\text { Servicios periféricos: } \\
\text { a) Alta inspección en cada CCAA } \\
\text { b) Direcciones provinciales de } \\
\text { Ceuta y Melilla }\end{array}$ \\
\hline 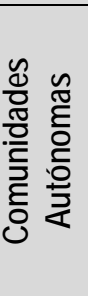 & $\begin{array}{l}\text { Titularidad administrativa en su territorio, creación, autorización y } \\
\text { funcionamiento de centros, gestión de personal, desarrollo de las } \\
\text { disposiciones del Estado en materia de programación de la enseñanza } \\
\text { regulación de los niveles, modalidades, grados y especialidades, } \\
\text { orientación y atención al alumnado, gestionan becas y ayudas al } \\
\text { estudio, facilitan el intercambio de información y la difusión de buenas } \\
\text { prácticas educativas o de gestión de los centros docentes, etc. }\end{array}$ & $\begin{array}{l}\text { Departamentos o Consejerías de } \\
\text { Educación de los respectivos } \\
\text { Gobiernos autonómicos }\end{array}$ \\
\hline 串 & $\begin{array}{l}\text { Provisión de solares para la construcción de centros públicos, } \\
\text { conservación, mantenimiento y reforma de los centros de Educación } \\
\text { infantil, de Educación Primaria y Educación Especial, programa de } \\
\text { actividades extraescolares y complementarias, vigilancia del } \\
\text { cumplimiento de la escolaridad obligatoria, creación de Consejos } \\
\text { Escolares de ámbito municipal, etc. }\end{array}$ & $\begin{array}{l}\text { Distintos servicios municipales de } \\
\text { educación }\end{array}$ \\
\hline \& $\frac{8}{8}$ & $\begin{array}{l}\text { Los centros escolares no universitarios poseen autonomía para la } \\
\text { gestión organizativa, pedagógica y económica. Esta autonomía tiene } \\
\text { como finalidad conseguir una mayor adecuación y aprovechamiento de } \\
\text { los recursos asignados y posibilitar un modelo de acción pedagógica } \\
\text { más ajustado a las necesidades específicas de los alumnos y a las } \\
\text { características del entorno escolar. }\end{array}$ & \\
\hline
\end{tabular}

Fuente: Red Europea de Información sobre Educación (EURYDICE, 2011).

La actual estructura de las enseñanzas que ofrece el sistema educativo español viene establecida en el art.3 de la LOMCE. En ella se distingue entre Enseñanzas de Régimen General, Enseñanzas de Régimen Especial y Enseñanza Superior. En la primera etapa está la Educación Infantil. La Educación Primaria, la Educación Secundaria Obligatoria (ESO) y Formación Profesional Básica constituyen la Educación Básica. La Educación Secundaria se divide en Educación Secundaria Obligatoria y Educación Secundaria Postobligatoria, abarcando esta última el Bachillerato, la Formación Profesional de grado medio, las Enseñanzas Profesionales de artes plásticas y diseño de grado medio, y las Enseñanzas deportivas de grado medio. Finalmente, la Educación Superior abarca la Enseñanza Universitaria, las Enseñanzas artísticas superiores, la Formación Profesional de grado superior, la Enseñanza Profesional de artes plásticas y diseño de grado superior, y las Enseñanzas deportivas de grado superior. De todas ellas, las Enseñanzas artísticas y las deportivas junto con las Enseñanzas de idiomas tendrán la consideración de Enseñanzas de Régimen Especial (Cuadro 2). 


\section{Cuadro 2}

Esquema del sistema educativo español según la LOMCE

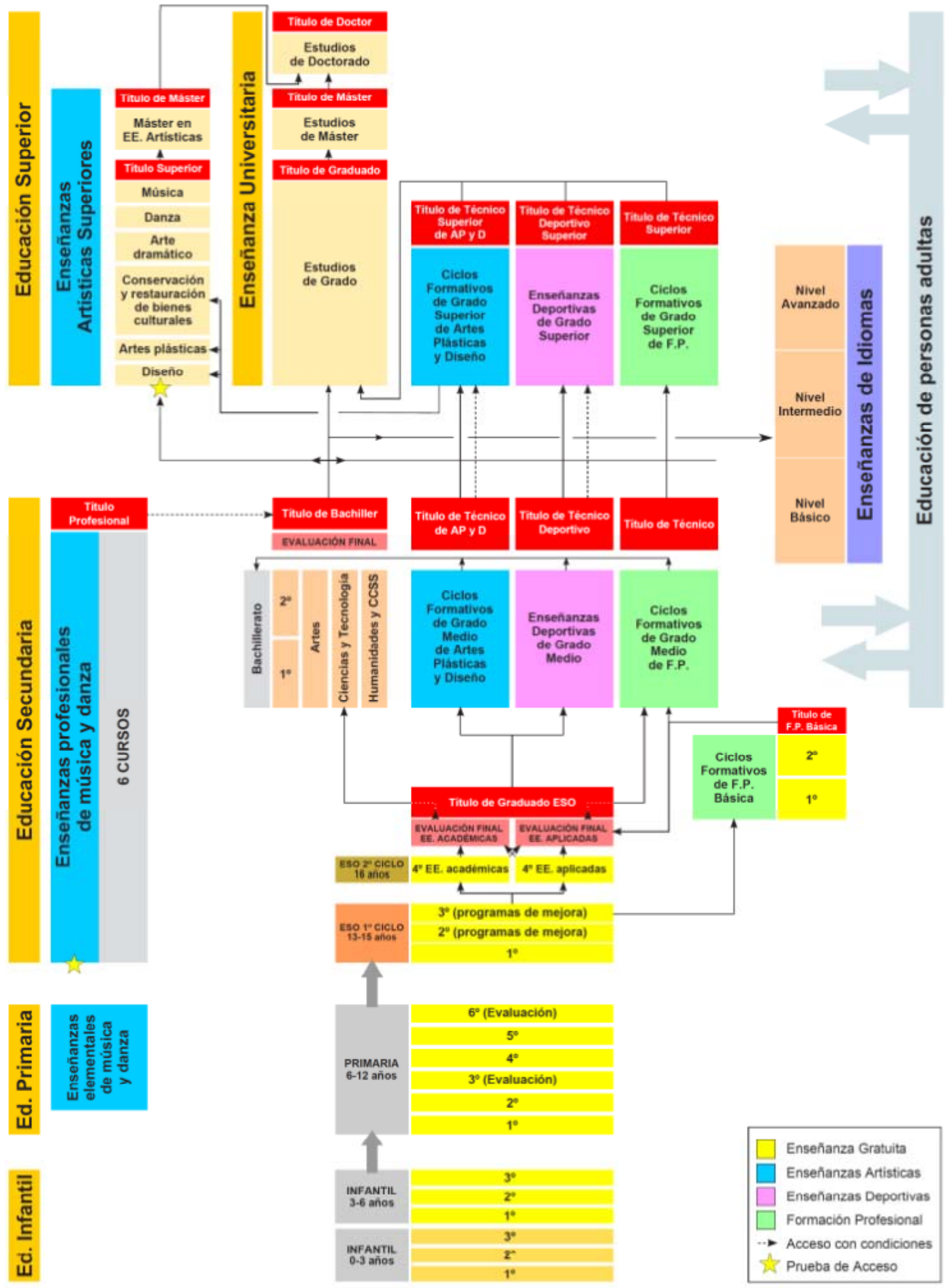

Fuente: Ministerio de Educación, Cultura y Deporte [www.educacion.gob.es]. 


\section{Gasto público en educación}

La educación en España está básicamente financiada con fondos públicos, aunque un pequeño porcentaje procede de fondos privados, tanto de instituciones privadas como de los propios usuarios del sistema educativo.

El objetivo del Gasto público en educación es la mejora de la igualdad de oportunidades, la formación de la mano de obra demandada por el sistema productivo y la contribución al desarrollo económico general del país.

El Gráfico 1 recoge, para CyL, la importancia relativa del gasto público en educación sobre dos variables macroeconómicas nacionales, el PIB y el Gasto Público Total, en comparación con el valor medio calculado para el total de CCAA. En el gráfico situado en la parte izquierda, se observa inicialmente un descenso en CyL de 0,2\% del gasto público en educación sobre el PIB, desde el año 2000 hasta el 2006, situándose hasta ese momento por encima de la media las CCAA. A partir de este año, la media de las CCAA crece exponencialmente, mientras que CyL se mantiene hasta el año 2009, cuando vuelve a alcanzar el valor que presentaba al inicio del periodo considerado.

En el gráfico situado en la parte derecha, CyL presenta un descenso pronunciado del peso del gasto público en educación sobre el Gasto Público Total a lo largo de todo el periodo, mientras que la media de todas las CCAA crece en los primeros cinco años, para posteriormente decrecer, finalizando en 2009 con un valor muy similar al obtenido en el año 2000.

\section{Gráfico 1}

\section{Gasto en educación en relación al PIB y al gasto público total}
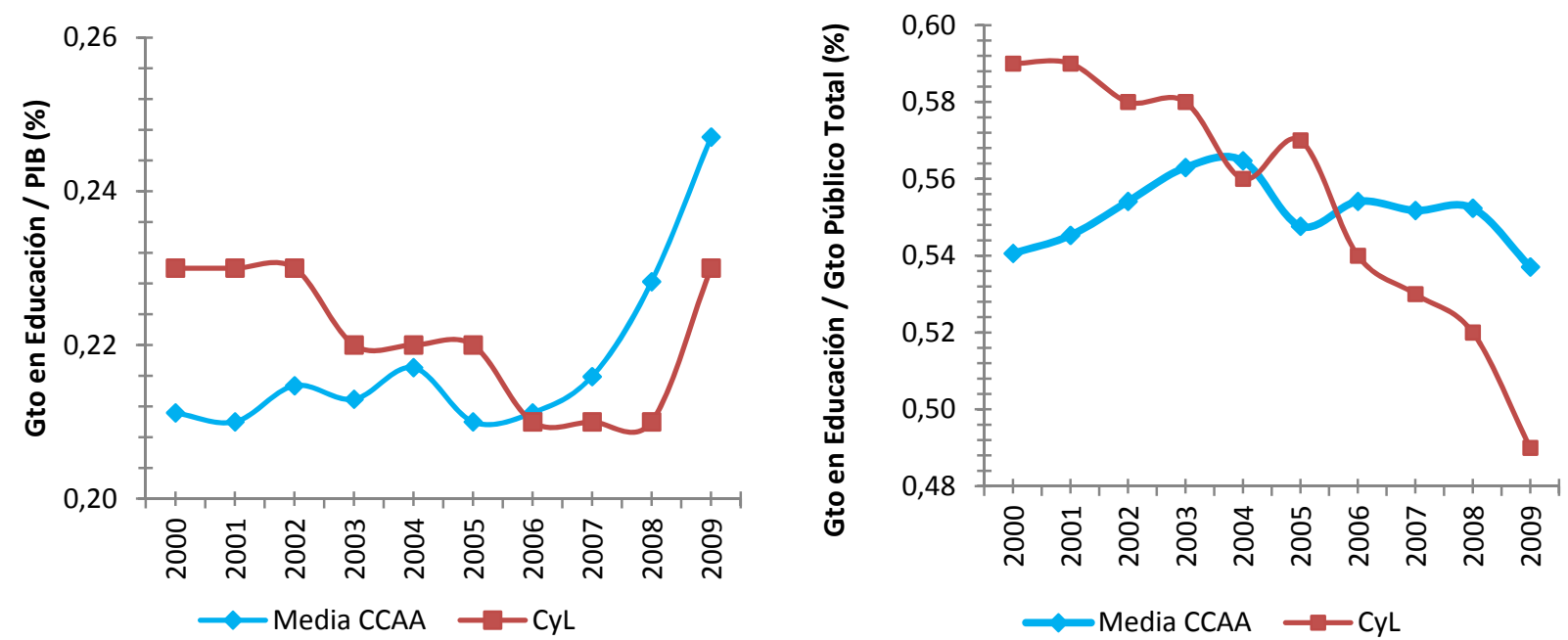

Fuente: Elaboración propia a partir de datos suministrados por el INE. Nota: El valor alcanzado por las variables en el año 2009 hace referencia a datos provisionales.

Dadas las características diferenciadoras que existen entre la enseñanza universitaria y no universitaria, se procede a analizar el gasto público que cada administración (Ministerio de Educación, Cultura y Deporte, y Administración Autonómica) destina a cada tipo de enseñanza.

\subsection{Gasto público en enseñanza no universitaria}

Castilla y León comienza a destinar fondos públicos de su presupuesto para la enseñanza no universitaria en el año 2000, una vez completado el proceso de descentralización de 
la educación no superior, cuyo inicio tiene lugar a partir de la aprobación de la Ley Orgánica 9/1992, de 23 de diciembre, finalizando con la publicación del Real Decreto 1340/1999, de 31 de julio.

Así, el porcentaje de fondos públicos que destina CyL a educación no universitaria, sobre el total de fondos asignados a educación del mismo tipo, decrece en un $0,8 \%$ entre los dos años extremos del periodo analizado, a pesar de que el importe en valores absolutos crece desde 1.070 .803 a 1.789 .620 miles de euros de 2000 a 2009, respectivamente, tal como se aprecia en el Gráfico 2. Del mismo modo, el MECD disminuye su porcentaje de aportación a lo largo del periodo, pero al contrario que ocurre en CyL el importe en valores absolutos decrece, principalmente, debido a la transferencia progresiva de las competencias en esta materia a las CCAA a lo largo del periodo. En el resto de las CCAA, tanto el porcentaje como el importe en euros crece en el intervalo temporal considerado, duplicando la cuantía en euros entre el año 2000 y 2009.

El objeto de esta disminución del porcentaje de fondos públicos destinados a la enseñanza no universitaria en CyL es tratar de beneficiarse de las economías de escala, al concentrar los centros escolares en las grandes urbes como consecuencia de la despoblación del medio rural. Por otra parte, esto también tiene efectos negativos en la calidad del servicio prestado como, por ejemplo, el empeoramiento del mantenimiento de los centros escolares, la reducción de contratación de personal, la merma de fondos para gastos corrientes de los centros escolares, etc.

\section{Gráfico 2}

Gasto público en enseñanza no universitaria (en \%)

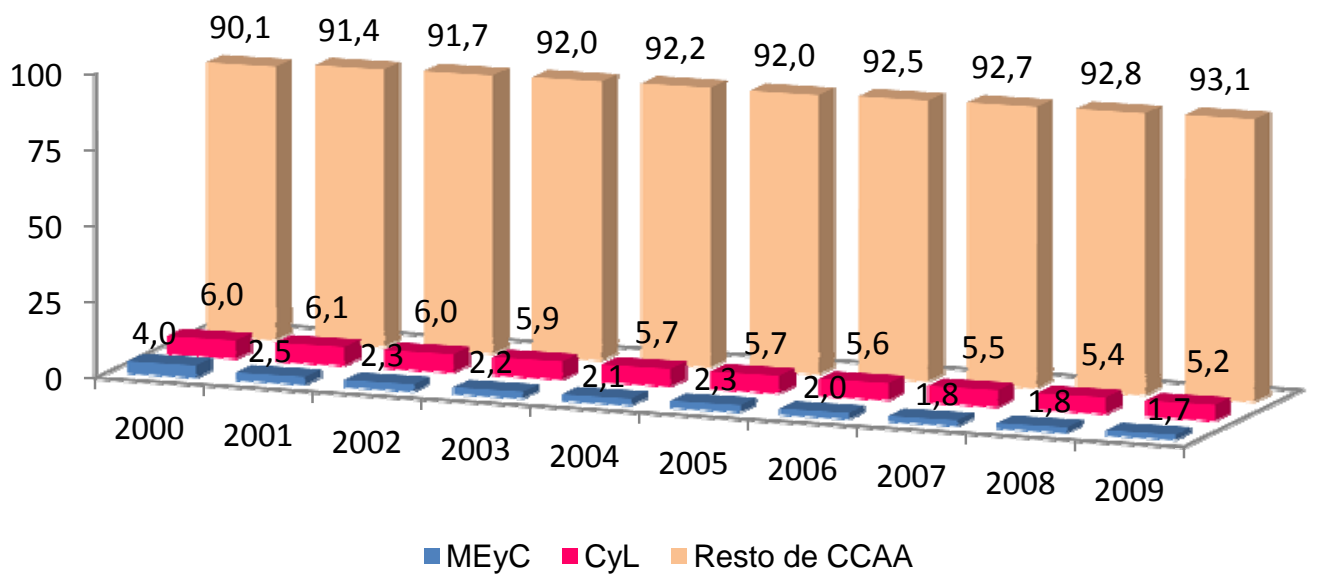

Fuente: Elaboración propia a partir de datos suministrados por el INE.

\subsection{Gasto público en enseñanza universitaria}

CyL es una de las últimas Comunidades Autónomas en adquirir las competencias en materia de educación superior tras la aprobación de la LRU. A partir de 1996, después de la publicación del Real Decreto 907/1995, de 2 de junio, comienza a asignar parte de su presu- puesto a la educación universitaria con un importe de 274.394 miles de euros en 1996 para ir creciendo hasta alcanzar algo más del doble de esa cuantía (579.641 miles de euros) en 2009.

Si se analiza el porcentaje de fondos públicos que destina CyL, el resto de CCAA y el MECD 
sobre el conjunto total de fondos destinados a enseñanza universitaria a nivel nacional, se puede comprobar que tanto CyL como el MECD disminuyen dicho porcentaje en un $1 \%$ y un $0,7 \%$,

\section{Gráfico 3}

\section{Gasto público en enseñanza universitaria}

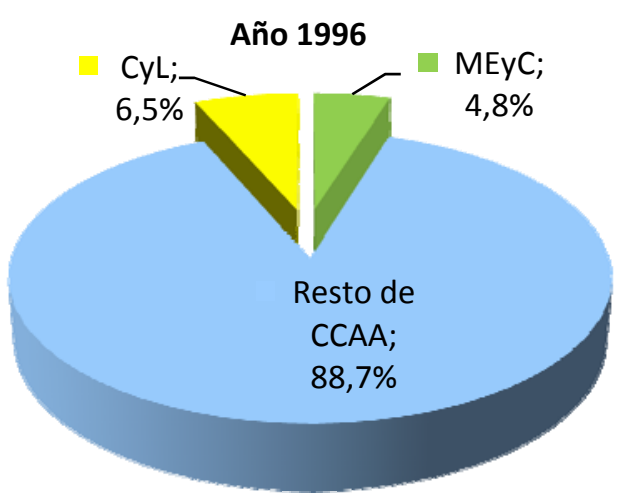

Fuente: Elaboración propia a partir de datos suministrados por el INE.

\subsection{Becas y ayudas al estudio}

Una parte del gasto público en educación se transfiere directamente a los alumnos a través de las becas y ayudas al estudio. Estas contribuyen a que los estudiantes, con menores recursos económicos y buena capacidad de estudio, tengan la oportunidad de acceder a la universidad y ayudar al crecimiento económico del país. Así, con estos recursos, los alumnos beneficiados logran cubrir una gran parte de sus gastos académicos, de residencia y desplazamiento.

En este apartado se van a estudiar tres indicadores que pueden ser útiles para medir la igualdad de oportunidades al estudio, como son: el número de becas recibidas, el número de becarios y el importe destinado a becas y ayudas al estudio. Todos ellos están representados en el Gráfico 4, en el que se hace referencia a la variación de los mismos entre los cursos 2001/02 y 2010/11, tanto para la enseñanza universitaria como no universitaria, así como para los ámbitos territoriales autonómico y nacional.

El número de becas concedidas aumenta año tras año en enseñanzas no universitarias tanto para respectivamente, en el año 2009 con respecto al año 1996, mientras que el resto de CCAA aumenta dicho porcentaje en un 1,7\% (Gráfico 3).

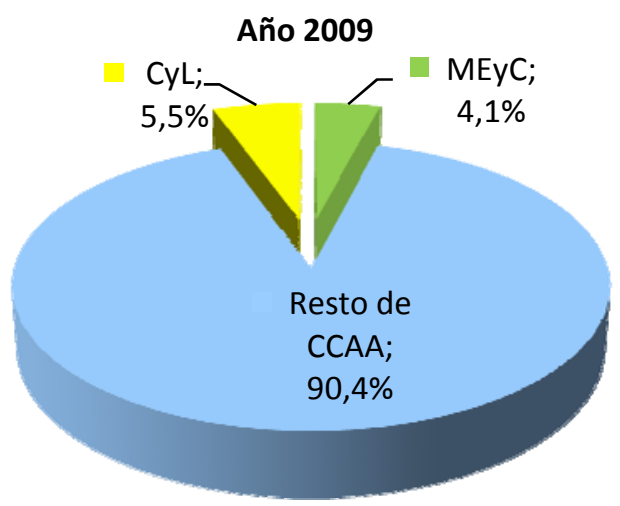

CyL como para España. Sólo en el curso 2010/11 se conceden más de 217.500 becas en CyL, frente a las 58.655 en 2001/02. En enseñanzas universitarias, el número de becas desciende un $8,8 \%$ en 2010/11 con respecto al 2001/02.

Del mismo modo que sucede con el número de becas concedidas, el número de becarios en enseñanzas no universitarias en CyL se incrementa entre los dos cursos académicos en un $306 \%$, pasando de 50.541 beneficiarios en 2001/02 a 205.527 en 2010/11. Sin embargo, la cantidad de estudiantes favorecidos con beca en enseñanzas universitarias sufre una caída del $10 \%$. A nivel nacional, este indicador aumenta ligeramente en ambos tipos de enseñanzas, aunque en enseñanzas universitarias (13,5\%) crece en menor proporción que en enseñanzas no universitarias $(45,5 \%)$.

Respecto al importe destinado a becas, se produce un incremento en CyL en los dos tipos de enseñanzas, destacando el aumento del $339 \%$ de las cuantías destinadas a enseñanza no universitaria entre los dos cursos académicos considerados frente al $195 \%$ en el ámbito nacional. 
Finalmente, podemos concluir que CyL ha sido favorecida en estos nueve cursos académicos (de 2001/02 a 2010/11) con respecto a total de España en la enseñanza no universitaria tanto en el número de becas, como número de becarios e importe destinado a las mismas. No se puede decir lo mismo para enseñanzas universitarias.

\section{Gráfico 4}

Número de becas, número de becarios, e importe destinado en CyL y España para ayudas al estudio

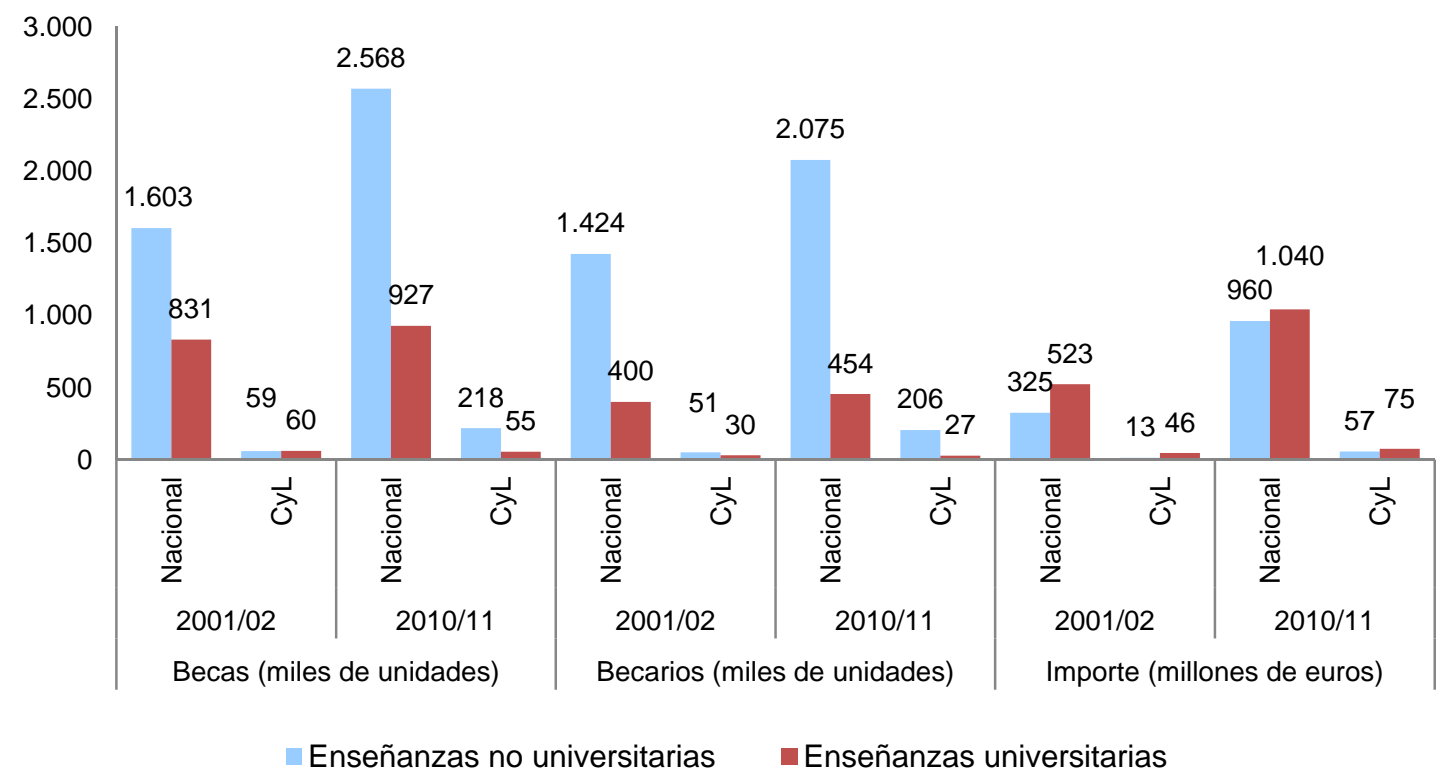

Fuente: Elaboración propia a partir de datos suministrados por el INE.

El incremento notable del importe destinado a becas en CyL en enseñanza no universitaria combinado con un aumento menos pronunciado de becarios, lleva a que la ratio "euros por becario" se incremente, pasando de 256 a 276 €/becario para los cursos 2001/02 y 2010/11, respectivamente. Importes ligeramente superiores a la media nacional en el primer periodo, pero considerablemente inferiores en el segundo periodo (Gráfico 5).

\section{Gráfico 5}

\section{Euros por becario recibidos en CyL, España y resto de CCAA}

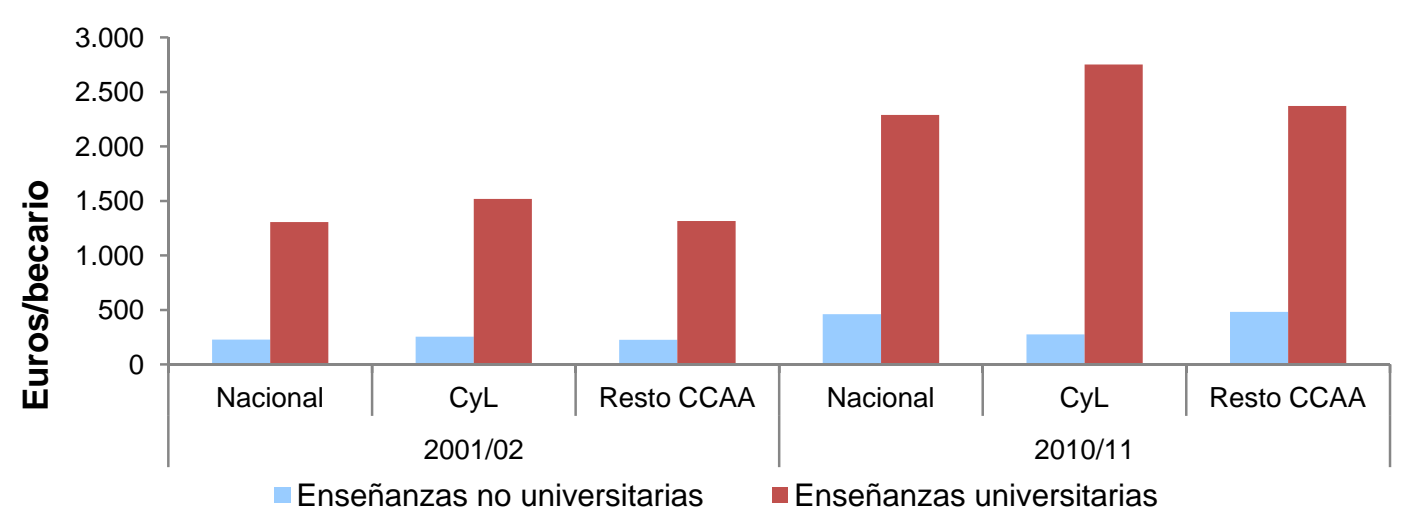

Fuente: Elaboración propia a partir de datos suministrados por el INE. 
Del mismo modo, en la enseñanza universitaria en CyL, la ratio "euros por becario" experimenta un incremento entre los dos cursos académicos, superando en ambos periodos a la media nacional, así como al resto de CCAA.

\section{E Sistema educativo en la provincia de León}

Para realizar este estudio se va a distinguir, al igual que se hizo en el apartado 3. Gasto público en educación, entre enseñanza universitaria y no universitaria, debido a sus características diferenciadoras.

\subsection{Enseñanzas de régimen general}

En este apartado se pretende analizar tres indicadores: número de alumnos matriculados en enseñanzas no universitarias, número de centros y número de unidades o grupos.

\subsubsection{Alumnos matric ulados en enseñanzas no universitarias}

El primero de los indicadores hace referencia al número de alumnos matriculados en educación infantil, educación primaria, y educación secun- daria, ya sea esta última obligatoria o postobligatoria.

Este indicador está representado gráficamente en el Gráfico 6, donde se observa la evolución del número de alumnos matriculados desde el curso 1986/87 hasta el 2010/11, considerando que el inició del periodo analizado presenta el valor 100. Como se puede observar, se produce en esta variable una disminución en la provincia de León a lo largo del tiempo del 40,5\%, siendo este descenso superior al experimentado en CyL y en España con tan sólo caídas del 33,5\% y $11,5 \%$, respectivamente. Esta variación negativa en la provincia de León se debe, en general, al descenso de la natalidad que también se produce a nivel nacional $y$, en particular, al éxodo de población hacia otras regiones con mayores oportunidades laborales.

Por otra parte, ni en la provincia de León, ni en CyL, la inmigración y, posteriormente, su descendencia tienen un efecto positivo como sucede a nivel nacional, contribuyendo a que la caída de estudiantes no sea tan significativa. Esto se debe a que los inmigrantes suelen concentrarse en las ciudades donde hay mayores posibilidades de trabajo, situación que no sucede ni a nivel provincial, ni autonómico.

\section{Gráfico 6}

Variación del número de alumnos en enseñanzas de régimen general

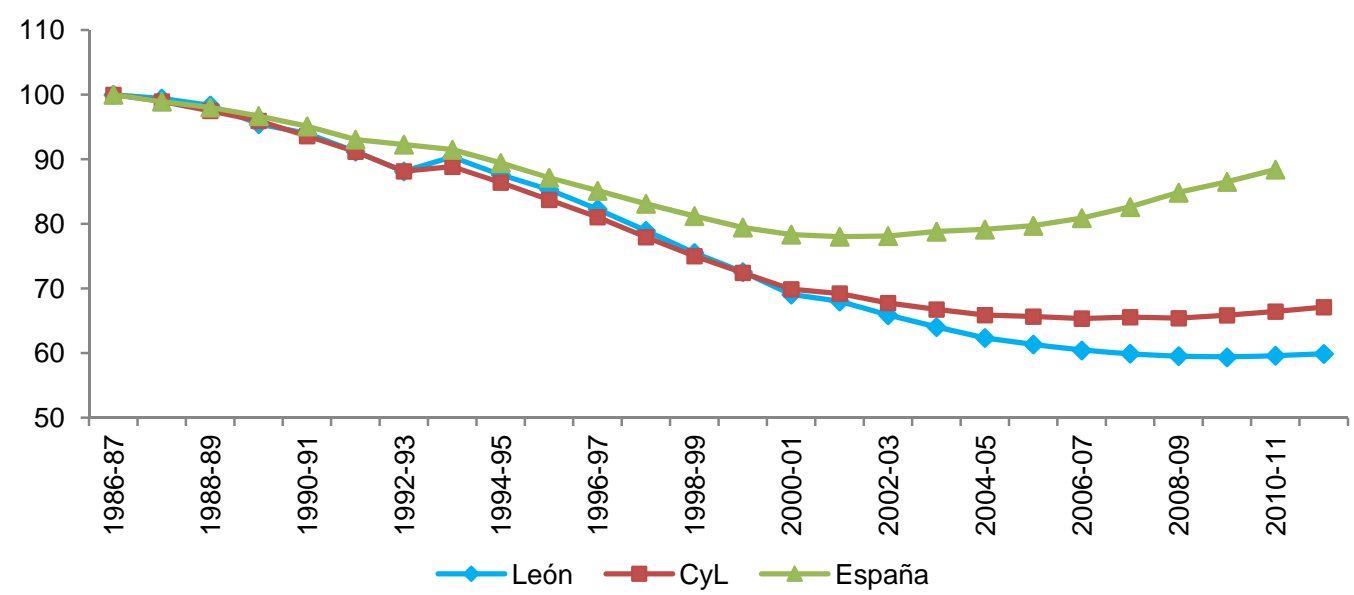

Fuente: Elaboración propia a partir de los Anuarios Estadísticos de Castilla y León, y el INE.

Nota: Enseñanzas de Régimen General: Educación Infantil, Educación Primaria, Educación Secundaria Obligatoria y Educación Secundaria Postobligatoria. 
Conviene aclarar que el cambio de normativa que regula el sistema educativo a lo largo de los años de estudio ha dado lugar al solapamiento de los datos referentes a la enseñanza secundaria obligatoria y postobligatoria, como se comprueba y se comenta en el apartado correspondiente.

A continuación se realiza un análisis del número de alumnos matriculados por cada etapa educativa no universitaria en los tres ámbitos territoriales analizados (provincial, autonómico y nacional) desde el curso académico 1986/87 hasta la actualidad.

\section{Educación infantil}

En la actualidad, la etapa de educación infantil está dividida en dos ciclos. El primero comprende hasta los tres años, y el segundo, desde los tres a los seis años de edad, siendo este último ciclo gratuito. Su finalidad es la de contribuir al desarrollo físico, afectivo, social e intelectual de los niños.

En el Gráfico 7 se puede apreciar la tendencia inicial bajista de los alumnos matriculados en Educación Infantil en los tres ámbitos territoriales. Esto se debe principalmente al descenso de la natalidad. No obstante, a nivel nacional la recuperación se vislumbra desde del curso 1991/92 y en mayor medida a partir de 1998/99, como consecuencia del efecto que produce el aumento de la tasa de natalidad de los españoles e inmigrantes. Sin embargo, en la provincia de León, el inicio de la recuperación no sucede hasta los cursos 1999/00 y 2000/01, no superando al final del periodo estudiado los niveles alcanzados en $1986 / 87$.

\section{Gráfico 7}

Variación temporal del número total de alumnos matriculados en educación infantil

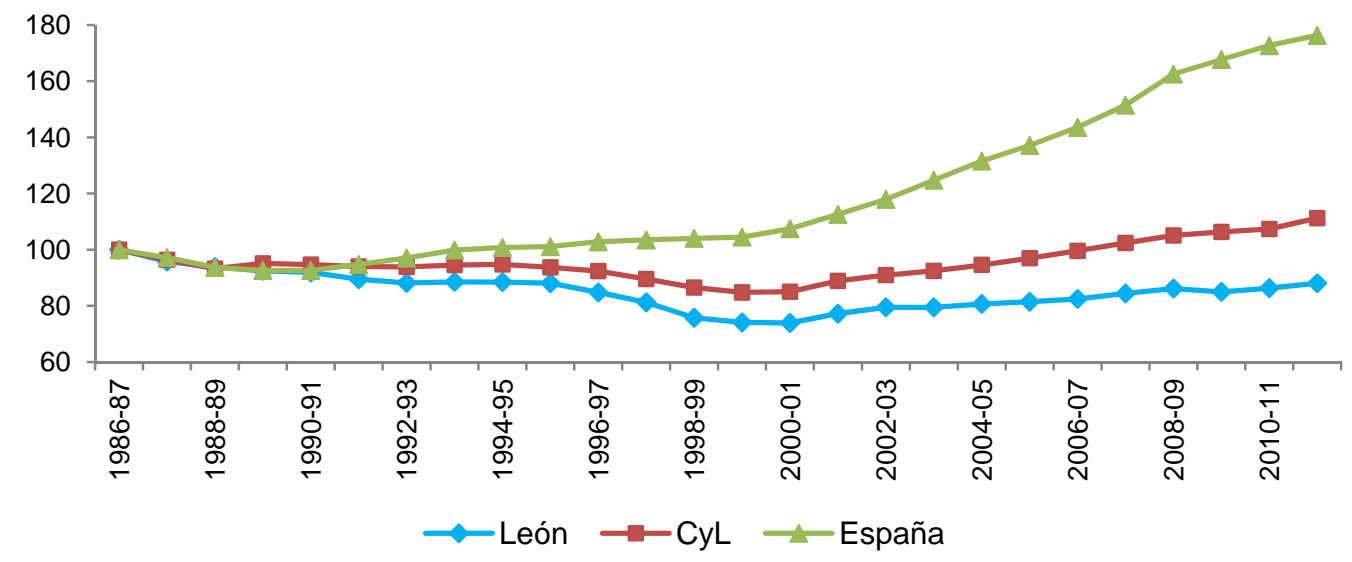

Fuente: Elaboración propia a partir de los Anuarios Estadísticos de Castilla y León, y el INE.

\section{Educación básica obligatoria}

La antigua Enseñanza General Básica ${ }^{4}$ (EGB), la actual Educación Primaria, que comprende tres ciclos de dos cursos cada uno, y la ESO, dividida en cuatro cursos, forman la denominada Educación Básica Obligatoria.

4 La EGB estaba formada por tres ciclos. El primer ciclo constaba de dos cursos $\left(1^{\circ}\right.$ y $\left.2^{\circ}\right)$, y los otros dos ciclos de tres cursos cada uno $\left(3^{\circ}, 4^{\circ}\right.$ y $5^{\circ}$; y $6^{\circ}, 7^{\circ}$ y $8^{\circ}$, respectivamente).
La ESO se empieza a implantar en algunas Comunidades Autónomas en el curso 1992/93 y en CyL en un curso posterior.

En el Gráfico 8 se recogen dos cuadros que hacen referencia al número de alumnos matriculados en EGB-Educación Primaria y en la ESO. Ambas representaciones se deben analizar conjuntamente al ser complementarias, ya que con la entrada en vigor de la LOGSE en 1991, los dos últimos cursos de los ocho que 
formaban la EGB, pasan a formar parte de la ESO, junto con los dos primeros del antiguo Bachillerato Unificado Polivalente (BUP). Por tanto, analizando ambos gráficos, la disminución del número de alumnos en EGB-Primaria supone una parte del aumento de los mismos en la ESO, constituyendo la otra parte de ese incremento la incorporación de los alumnos que anteriormente cursaban primero y segundo de BUP.

\section{Gráfico 8}

\section{Evolución del número de alumnos matriculados en EGB-Primaria y ESO}
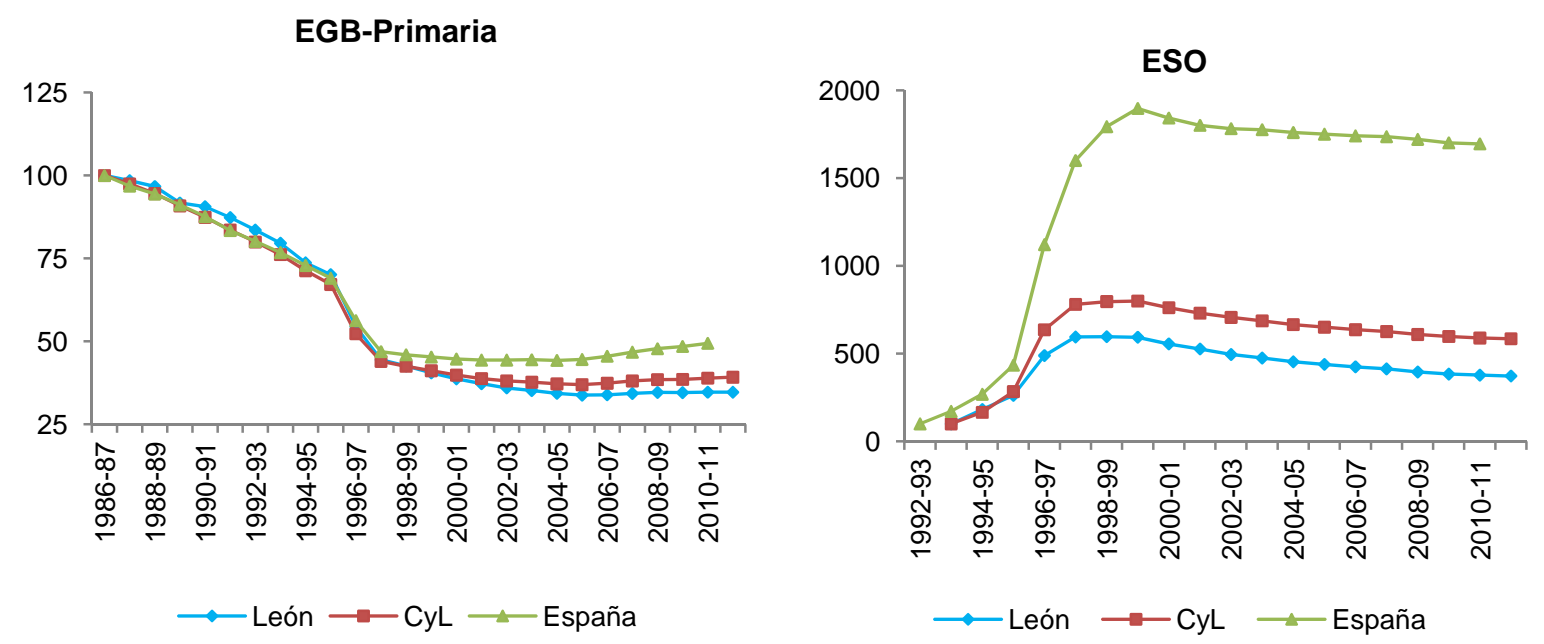

Fuente: Elaboración propia a partir de Anuarios Estadísticos de los Castilla y León, y el INE.

Respecto a la evolución temporal en cada territorio, hay que destacar la situación que presentan la provincia de León y CyL, posicionándose muy por debajo del incremento que experimenta el número de alumnos matriculados en ESO a nivel nacional a partir del curso 1996/97 debido, tal como ya se comentó en el apartado "4.1.1 Alumnos matriculados en enseñanzas no universitarias" análisis de la educación infantil, al menor aumento de la natalidad en la provincia de León y en CyL con respecto a España y al efecto del éxodo de la población.

También hay que mencionar los Programas de Garantía Social o Programas de Cualificación Profesional Inicial (PCPI). Se tratan de programas de formación dirigidos a jóvenes sin cualificación profesional, con el fin de mejorar su formación general y capacitarles para realizar determinados oficios, trabajos y perfiles profesionales, facilitando, por tanto, su inserción laboral o reinserción educativa. Están destinados generalmente a jóvenes comprendidos entre 16 y 21 años que no hayan alcanzado los objetivos de la ESO y no posean titulación de Formación Profesional. Dado que el análisis de esta etapa educativa en la provincia de León es muy poco significativo, no se consideran en este estudio.

\section{Enseñanza postobligatoria}

La anterior LGE estableció que la enseñanza postobligatoria debía comprender el Bachillerato Unificado Polivalente (BUP), el Curso de Orientación Universitaria (COU) y la Formación Profesional (FP).

Con posterioridad, la LOGSE y más tarde la LOE, que derogan la anterior LGE, determinan como enseñanzas postobligatorias el Bachillerato y los Módulos Profesionales o Ciclos Formativos.

A) BUP-COU y Bachillerato (LOGSE)

El ya extinguido BUP constaba de 3 cursos, al final de los cuales el alumno estaba capacitado 
para recibir el Título de Bachiller, que permitía el acceso bien a la Formación Profesional de segundo grado, o bien, al Curso de Orientación Universitaria (COU), que constituía la vía normal de acceso a la Universidad. La reforma del sistema educativo transforma estas enseñanzas en parte de la nueva educación obligatoria (segundo ciclo de Educación Secundaria Obligatoria) más un corto Bachillerato de dos años de duración, que engloba el extinguido COU.

La enseñanza en Bachillerato (LOGSE) inicia su andadura en CyL en el curso 1993/94, y algunas Comunidades Autónomas en el curso anterior.

En el Gráfico 9 se representa la evolución del número de alumnos matriculados en las enseñanzas de BUP-COU (parte izquierda) y Bachillerato (LOGSE) (parte derecha). Ambos deben ser analizados conjuntamente, e incluso considerar el gráfico que hace referencia a los alumnos de ESO analizado en el apartado anterior. En ellos, se puede apreciar que la disminución del número de alumnos matriculados en BUP-COU a partir del 1992/93 va acompañada de un aumento en el Bachillerato (LOGSE), aunque no tan notable como el descenso en BUP-COU, debido a que los alumnos que cursaban primero y segundo de BUP ahora pasan a tercero y cuarto de la ESO.

Si se analiza el número de alumnos en valores absolutos, se observa un descenso considerable del número de estudiantes en estas enseñanzas en el periodo de estudio (1986/87 a 2010/11) del $61 \%, 60 \%$ y $47 \%$ según los ámbitos territoriales a los que se refieran (provincial, autonómico y nacional, respectivamente). Esto se debe al descenso de la natalidad $y$, en mayor medida, al acortamiento de los años de estudio en el Bachillerato (LOGSE) que pasa de cuatro, en el antiguo BUP-COU, a dos en la actual estructura de la enseñanza no universitaria.

\section{Gráfico 9}

\section{Evolución temporal del número de alumnos matriculados en BUP-COU y Bachillerato (LOGSE)}
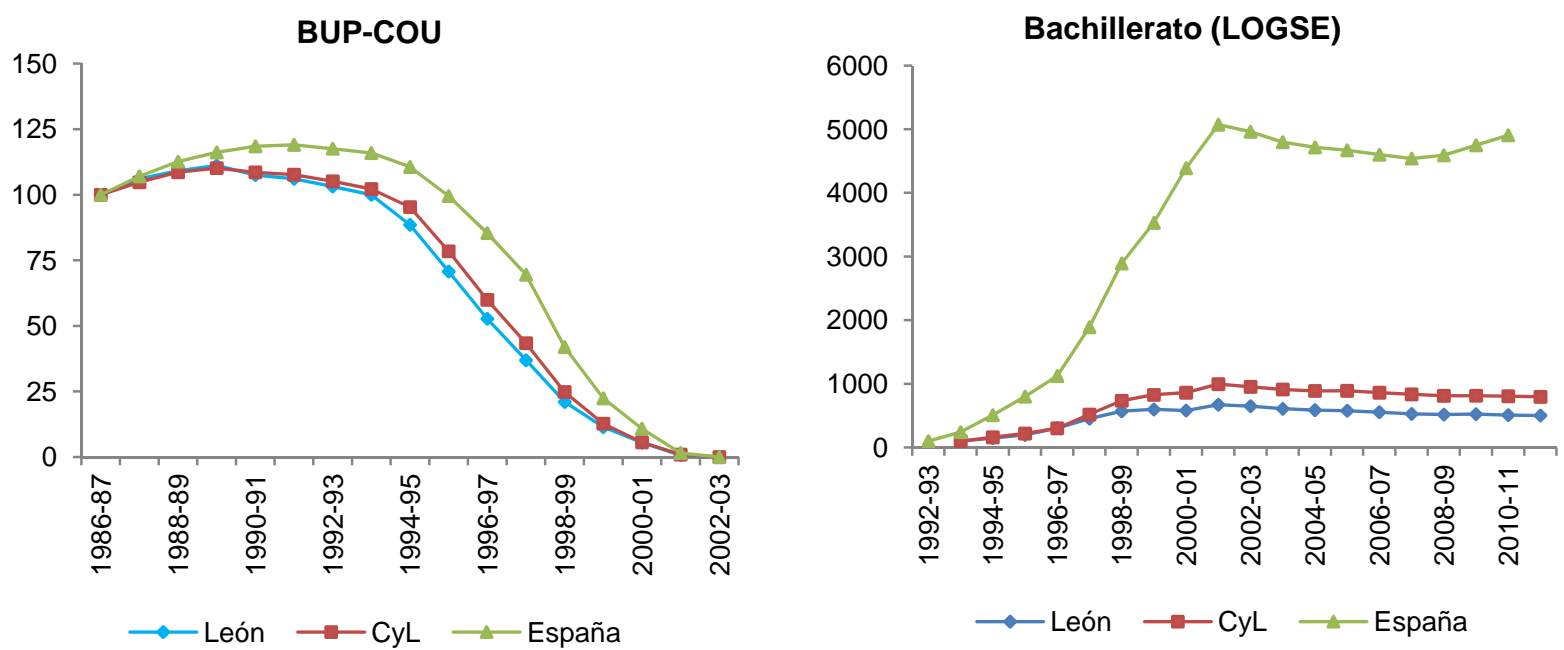

Fuente: Elaboración propia a partir de Anuarios Estadísticos de los Castilla y León, y el INE.

B) La Formación Profesional (FP) y los Módulos Profesionales - Ciclos Formativos (MP-CF)

La Formación Profesional actual, también denominada Módulos Profesionales - Ciclos Formativos
(MP-CF), comprende el conjunto de enseñanzas que, dentro del sistema educativo, capacitan para el desempeño cualificado de las distintas profesiones. Incluye tanto la formación profesional de base, llamados Programas de Cualificación 
Profesional Inicial (PCPI) ${ }^{5}$, como la Formación Profesional específica de grado medio y superior.

Los MP-CF comienzan a implantarse en el curso 1993/94 en CyL, y la antigua FP deja de impartirse en el curso 2001/02.

La evolución de los alumnos matriculados a lo largo del tiempo en las enseñanzas de FP y MP-CF debe ser analizada de forma complementaria, ya que durante el periodo 1993/94 y 2001/02 se solapan ambas enseñanzas, como consecuencia del inicio y crecimiento progresivo de los MP-CF y la disminución paulatina de la FP hasta su extinción en 2001/02.

A nivel territorial, la antigua FP sufre una disminución clara del número de alumnos matriculados en la provincia de León desde el curso 1986/87. No ocurre lo mismo en CyL y en España, donde el descenso no comienza hasta el curso 1992/93 (Gráfico 10). Por el contrario, el número de alumnos matriculados en MP-CF aumenta de forma progresiva en los tres ámbitos territoriales a partir del primer curso de impartición (1993/94), notándose más intensamente a partir del curso 1995/96. Si bien este crecimiento no es tan fuerte en la provincia de León como en CyL o España.

Si nos centramos en el número absoluto de alumnos matriculados, destaca una evidente disminución del 37,5\%, 36,1\% y 22,6\% desde el primer curso analizado 1986/87 hasta el 2010/11 en los tres ámbitos territoriales (provincial, autonómico y nacional, respectivamente). Esto significa que los estudiantes siguen sin encontrar atractiva la profesionalización a través de este tipo de enseñanzas.

\footnotetext{
5 Hacen referencia a los Programas de Garantía Social ya comentados en el apartado 4.1.3. Educación básica obligatoria.
}

\section{Gráfico 10}

Evolución temporal del número de alumnos matriculados en FP antiguo y Módulos Profesionales - Ciclos Formativos
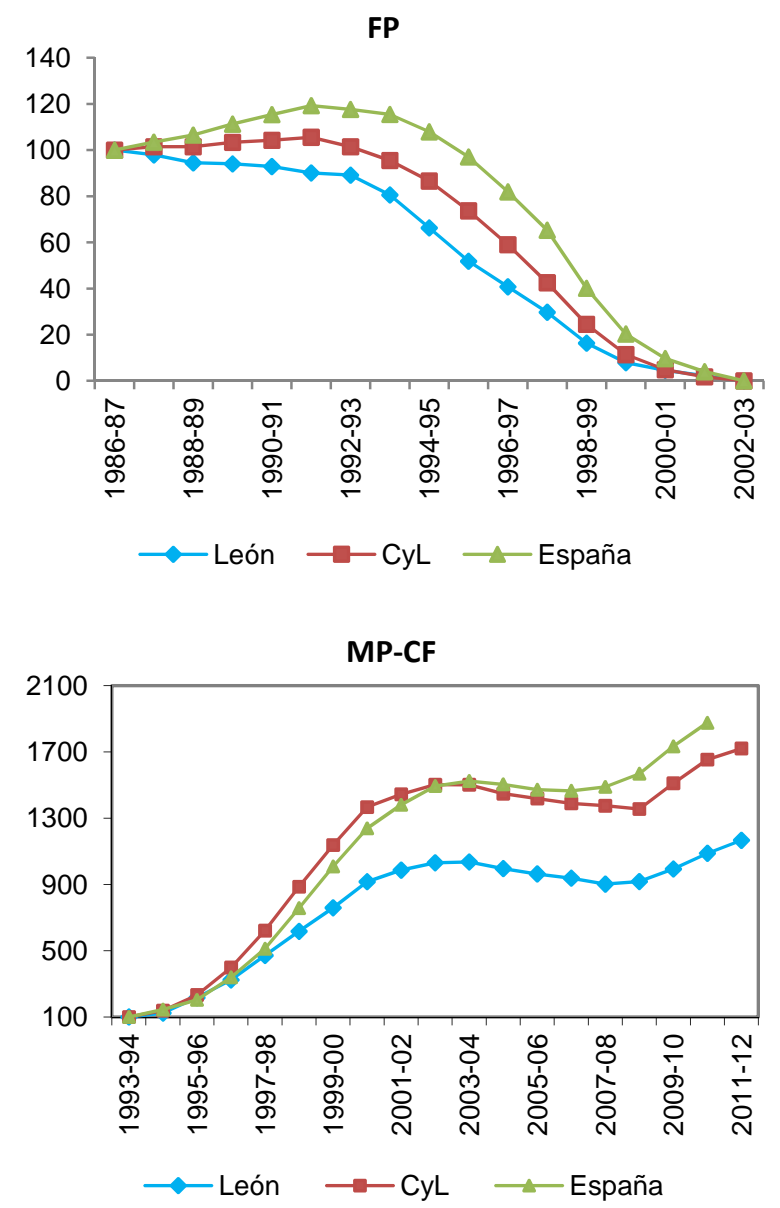

Fuente: Elaboración propia a partir de los Anuarios Estadísticos de Castilla y León, y el INE.

\subsubsection{Centros y unidades/grupos en Ense- ñanza de Régimen General}

Otros indicadores que muestran la evolución de la Enseñanza de Régimen General no universitaria son el número de centros y el número de unidades/grupos.

En la Tabla 1 se recoge el valor absoluto de estos indicadores por etapas de enseñanza de régimen general en la provincia de León desde 1986/87 a 2011/12, así como el porcentaje de los mismos que corresponden a centros o unidades/grupos de enseñanza pública. 
Tabla 1

Número de centros y unidades/grupos por etapa de Enseñanzas de Régimen General en la provincia de León

\begin{tabular}{|c|c|c|c|c|c|c|c|c|c|c|c|c|}
\hline & \multicolumn{6}{|c|}{$\mathrm{N}^{0}$ de Centros } & \multicolumn{6}{|c|}{$\mathrm{N}^{0}$ de unidades / grupos } \\
\hline & \multicolumn{2}{|c|}{ Educación Infantil } & \multicolumn{2}{|c|}{$\begin{array}{c}\text { EGB/Primaria y } \\
\text { ESO (LOGSE) }\end{array}$} & \multicolumn{2}{|c|}{$\begin{array}{c}\text { BUP, COU Y } \\
\text { BACHILLERATO } \\
\text { (LOGSE) }\end{array}$} & \multicolumn{2}{|c|}{$\begin{array}{c}\text { Educación } \\
\text { Infantil }\end{array}$} & \multicolumn{2}{|c|}{$\begin{array}{c}\text { EGB/Primaria y } \\
\text { ESO (LOGSE) }\end{array}$} & \multicolumn{2}{|c|}{$\begin{array}{c}\text { BUP, COU Y } \\
\text { BACHILLERATO } \\
\text { (LOGSE) }\end{array}$} \\
\hline & Total (1) & \%Públ. & Total & \%Públ. & Total & \% Públ. & Total & \%Públ. & Total & \%Públ. & Total & \%Públ. \\
\hline $1986-87$ & 33 & 66,7 & 519 & 91,1 & 43 & 53,5 & 497 & 77,7 & 2217 & 76,8 & & \\
\hline 1987-88 & 32 & 71,9 & 277 & 97,5 & 44 & 56,8 & 906 & 44,3 & 4316 & 44,1 & & \\
\hline 1988-89 & 30 & 60 & 266 & 97,4 & 44 & 56,8 & 502 & 78,7 & 2184 & 23,3 & & \\
\hline $1989-90$ & 33 & 60,6 & 254 & 97,6 & 44 & 56,8 & 501 & 77,6 & 2135 & 76,5 & & \\
\hline $1990-91$ & 33 & 60,6 & 235 & 98,3 & 44 & 56,8 & 511 & 78,1 & 2142 & 76,6 & & \\
\hline $1991-92$ & 20 & 40 & 476 & 91 & 46 & 58,7 & 543 & 77,3 & 2317 & 78,2 & & \\
\hline $1992-93$ & 18 & 44,4 & 467 & 91 & 44 & 56,8 & 558 & 77,2 & 2275 & 78,2 & & \\
\hline 1993-94 & 15 & 46,7 & 339 & 87,6 & 53 & 66 & 553 & 77,8 & 2052 & 75,8 & & \\
\hline 1994-95 & 15 & 40 & 214 & 76,2 & 53 & 66 & 554 & 78,3 & 1951 & 76,7 & & \\
\hline 1995-96 & 13 & 38,5 & 216 & 77,3 & 55 & 70,9 & 538 & 77,7 & 2481 & 79,8 & 482 & 74,3 \\
\hline 1996-97 & 169 & 78,7 & 197 & 73,6 & 57 & 73,7 & 530 & 78,3 & 1876 & 76,8 & 444 & 73,6 \\
\hline 1997-98 & 165 & 78,8 & 312 & 76,9 & 64 & 73,4 & 527 & 77 & 2262 & 77,7 & 429 & 73,4 \\
\hline 1998-99 & 166 & 78,3 & 312 & 76,9 & 63 & 74,6 & 522 & 76,2 & 2449 & 77,6 & 408 & 78,2 \\
\hline 1999-00 & 164 & 78,7 & 310 & 76,8 & 57 & 71,9 & 505 & 74,1 & 2252 & 74 & 380 & 83,9 \\
\hline 2000-01 & 162 & 79 & 307 & 77,5 & 65 & 61,5 & 517 & 74,5 & 2219 & 73,7 & 368 & 84,0 \\
\hline 2001-02 & 171 & 78,4 & 306 & 77,5 & 55 & 70,9 & 544 & 73,2 & 2344 & 75 & 354 & 82,5 \\
\hline $2002-03$ & 174 & 77,6 & 260 & 75 & 53 & 69,8 & 583 & 73,4 & 2364 & 75,4 & 360 & 81,7 \\
\hline 2003-04 & 174 & 78,2 & 257 & 75,1 & 53 & 69,8 & 583 & 72,9 & 2196 & 74,1 & 333 & 82,0 \\
\hline 2004-05 & 173 & 78 & 254 & 74,8 & 53 & 69,8 & 610 & 73,8 & 2136 & 73,9 & 326 & 81,3 \\
\hline 2005-06 & 171 & 77,8 & 250 & 75,2 & 52 & 69,2 & 592 & 70,8 & 2104 & 73,3 & 330 & 81,2 \\
\hline 2006-07 & 171 & 77,8 & 250 & 75,2 & 52 & 69,2 & 592 & 69,8 & 2087 & 73,2 & 312 & 80,1 \\
\hline 2007-08 & 160 & 79,4 & 250 & 75,2 & 53 & 67,9 & 599 & 70,8 & 2052 & 72,8 & 289 & 78,5 \\
\hline 2008-09 & 161 & 79,5 & 250 & 75,6 & 54 & 66,7 & 623 & 70,9 & 2014 & 72,5 & 280 & 78,6 \\
\hline 2009-10 & 159 & 79,9 & 247 & 75,3 & 53 & 67,9 & 613 & 70 & 1977 & 72,2 & 258 & 76,4 \\
\hline 2010-11 & 160 & 80 & 248 & 75,4 & 53 & 67,9 & 615 & 68,9 & 1942 & 72 & 258 & 76,7 \\
\hline 2011-12 & 160 & 80 & 246 & 75,2 & 53 & 67,9 & 633 & 70,9 & 1928 & 71,9 & 258 & 76,0 \\
\hline
\end{tabular}

Fuente: Elaboración propia a partir de los Anuarios Estadísticos de Castilla y León.

Nota (1): Desde el curso 1986/87 hasta 1995/96 se recogen únicamente los Centros que tienen sólo el nivel de Preescolar o Infantil.

Analizando conjuntamente el número de centros y grupos escolares, se puede observar, por lo general, una disminución de ambas variables, especialmente en el grupo de enseñanzas de EGB/Primaria y ESO. Esto se debe principalmente a la clausura de centros en la zona rural, como consecuencia de la despoblación de la misma, que ha motivado su concentración en las grandes urbes del territorio provincial, así como al descenso de la natalidad. El objetivo de las decisiones tomadas, en este sentido, por la Administración Autonómica es la reducción de los costes, atendiendo al mayor número de estudiantes posibles, es decir, mejorar la eficiencia de los fondos públicos empleados en educación.

Por otra parte, el número de centros públicos aumenta ligeramente en Educación Infantil $(1,3 \%)$ desde 1996/97 hasta 2011/12. Sin 
embargo, se produce una disminución en EGB/ Primaria y ESO en el periodo de estudio de un $15,9 \%$, debido principalmente a la proliferación de centros concertados ${ }^{6}$.

En cuanto al número de grupos, el descenso es más pronunciado en Educación Infantil (6,8\%) frente a EGB/Primaria y ESO (4,9\%). Para el grupo de enseñanzas BUP, COU y Bachillerato (LOGSE), se puede observar un incremento del número de centros del $14,4 \%$ y de grupos de $1,7 \%$ en el periodo considerado.

\section{Enseñanza universitaria}

La Universidad se edifica sobre tres pilares básicos: docencia, con la formación de recursos humanos altamente cualificados; investigación, con la indagación de nuevos conocimientos; $y$, transferencia de conocimiento entre la institución de educación superior y la sociedad.

La Universidad de León (ULE) se crea formalmente en el año 1979, iniciando su andadura con 8 estudios: Veterinaria, Ciencias Biológicas, Educación, Minas, Agronomía, Filosofía y Letras, y Derecho, dependientes hasta ese momento de la Universidad de Oviedo. No obstante, algunas de estas enseñanzas se remontan a 150 años atrás, concretamente, en 1852 se crea la Escuela Subalterna de Veterinaria, antecesora de la Facultad de Veterinaria.

Actualmente, la oferta educativa de esta institución se reparte en dos campus: el de Vegazana, situado en León, donde se concentran la mayoría de las facultades y titulaciones y, a partir de 1996, el Campus de Ponferrada especializado en titulaciones de ingenierías y ciencias de la salud.

La Universidad de León ha ido incrementando progresivamente su oferta educativa a lo largo del periodo de estudio, partiendo de 12 titulaciones en el periodo 1986/87 (3 Ingenierías Técnicas, 4 Diplomaturas y 5 Licenciaturas) frente a las 37

\footnotetext{
6 Los colegios privados concertados son centros cuyos gastos escolares están prácticamente subvencionados por la Administración Pública.
}

titulaciones existentes en el curso 2010/11 (4 Ingenierías Superiores, 18 Licenciaturas, 9 Diplomaturas y 6 Ingenierías Técnicas) (Gráfico 11) ${ }^{7}$.

\section{Gráfico 11}

Número de titulaciones en la Universidad de León

Junta de Castilla y León, y del INE.

Este aumento de la oferta de enseñanzas universitarias por la ULE contribuye a que muchos estudiantes no se vean obligados a salir fuera de la provincia para cursar los estudios deseados, observándose, a su vez, una mayor afluencia de alumnos que proceden de otras provincias.

A este respecto, en el Gráfico 12 se puede observar la evolución del número de alumnos matriculados en la ULE a lo largo del periodo de estudio, destacando un incremento continuo hasta 1996/97, estabilización hasta 1999/00 y, posterior disminución paulatina hasta 2009/10. Este descenso en el último tercio del periodo considerado se debe a la caída de la tasa bruta de natalidad en los años 80 y 90 con un descenso máximo del 35\% entre 1986 y 1999 en la provincia de León, lo que repercute en el número de alumnos matriculados en la ULE en los años posteriores.

\footnotetext{
7 No se han tenido en cuenta los títulos de Grado que se han venido implantando progresivamente en la ULE desde el curso académico 2009/10, porque la gran mayoría de ellos equivalen a titulaciones ya existentes, sean ingenierías, licenciaturas o diplomaturas.
} 
Esta variación del número de estudiantes matriculados en la ULE se produce casi al mismo ritmo que sucede en el conjunto de las mismas titulaciones a nivel autonómico y nacional, con la particularidad de que, en la primera tercera parte del intervalo temporal, la ULE se posiciona por debajo de los otros dos ámbitos territoriales, sobrepasando a Castilla y León a mediados de los años 90, y manteniéndose por encima de ésta hasta el final del periodo, lo que confirma lo anteriormente expuesto en cuanto a la disminución del éxodo de alumnos de la provincia de León hacia otras universidades y el aumento del alumnado procedente de fuera de la provincia hacia titulaciones que comienzan a impartirse en la ULE.

Por otro lado, en el Gráfico 12 también se muestra la evolución que experimentan los alumnos egresados pertenecientes a las mismas titulaciones en la ULE como en la Comunidad Autónoma o en España a lo largo del intervalo de temporal de estudio. En él se puede apreciar el incremento de los egresados en los tres ámbitos territoriales, destacando un mayor crecimiento de la ULE con respecto a los otros dos, sobre todo en la segunda mitad del periodo considerado.

\section{Gráfico 12}

\section{Evolución del número de alumnos matriculados y egresados en las carreras universitarias ofertadas en} la Universidad de León
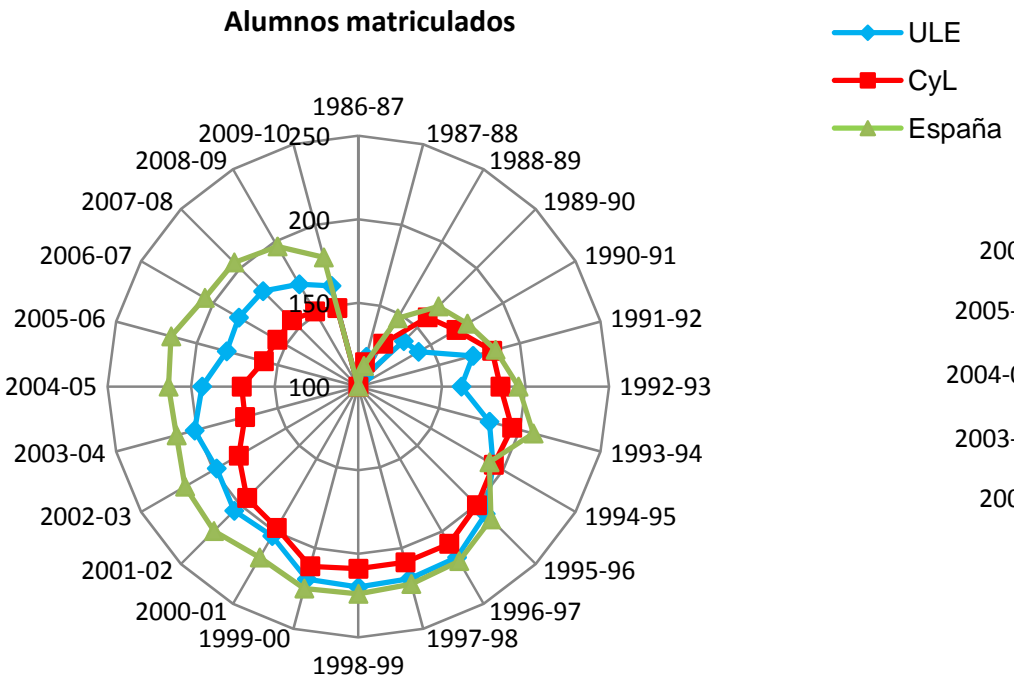

\section{Alumnos egresados}

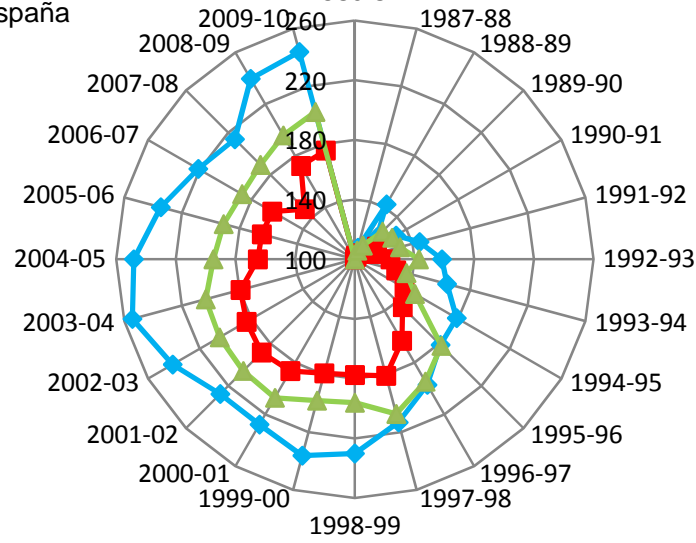

Fuente: Elaboración propia a partir los Anuarios Estadísticos de Castilla y León, y el INE. Nota: La no disposición de datos sobre alumnos matriculados en el curso 1997/98 y alumnos egresados en los cursos 1996/97, 2002/03 y 2005/06 se ha solucionado calculando la media entre el año anterior y el posterior.

Sin embargo, lo comentado en los párrafos anteriores no se traduce en una mayor proporción del número de alumnos egresados sobre los matriculados en la ULE, con respecto a CyL o a España, sino que este indicador en la ULE se posiciona en la mayoría de los cursos académicos por debajo de ambos, tal como se manifiesta en el Gráfico 13. Esta situación puede deberse al establecimiento de nuevas titulaciones en la ULE que implica que, en los primeros años de la enseñanza, aumente progresivamente el número de alumnos matriculados y no existan egresados hasta que no se haya completado el ciclo completo de las mismas. 


\section{Gráfico 13}

Ratio estudiantes egresados por estudiantes matriculados en la ULE

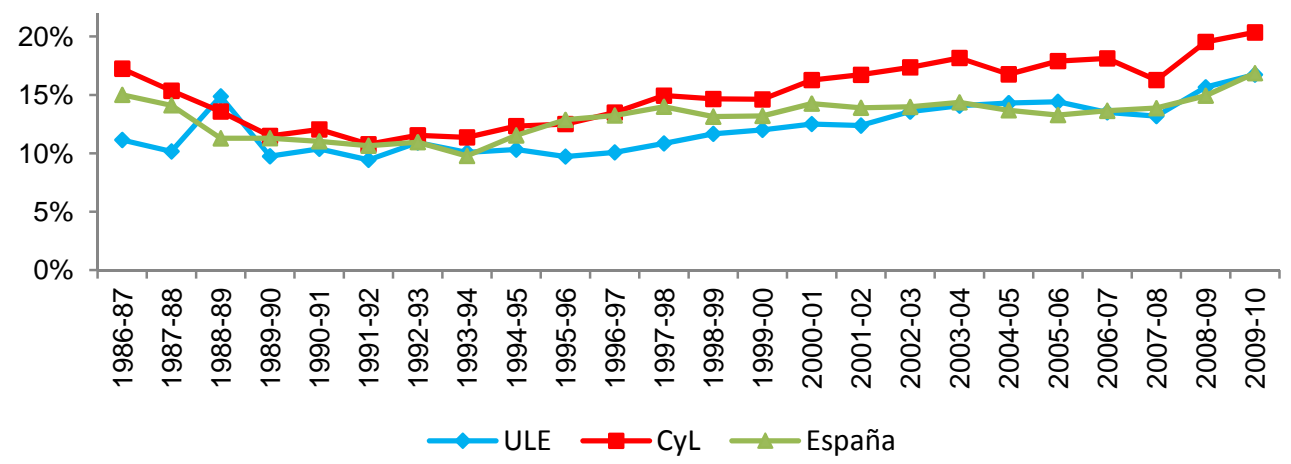

Fuente: Elaboración propia a partir los Anuarios Estadísticos de Castilla y León, y el INE.

Por otra parte, un estudio general por sexo indica que el número de mujeres matriculadas en la ULE aumenta con respecto a los hombres entre los cursos $1986 / 87$ y 2009/10, pasando del $49 \%$ a casi el $57 \%$ del total de alumnos, respectivamente. De forma análoga, los porcentajes obtenidos a nivel autonómico y nacional se sitúan ligeramente por encima de los obtenidos en la ULE.

Un análisis por sexo y rama de actividad en la ULE revela que los hombres prefieren titulaciones relacionadas con la rama de Ingeniería y
Arquitectura, mientras que las mujeres prefieren titulaciones relacionadas con Ciencias de la Salud, Ciencias, Artes y Humanidades, y Ciencias Sociales y Jurídicas, tal como se muestra en el Gráfico 14.

Si se hace un análisis temporal, se puede apreciar que las mujeres aumentan en la rama de Ingeniería y Arquitectura, Ciencias Sociales y Jurídicas, Ciencias y, notablemente, en Ciencias de la Salud en el curso 2009/10 con respecto al 1986/87.

\section{Gráfico 14}

Alumnos matriculados en la Universidad de León en los cursos 1986/87 y 2009/10 por rama de enseñanza y por sexo

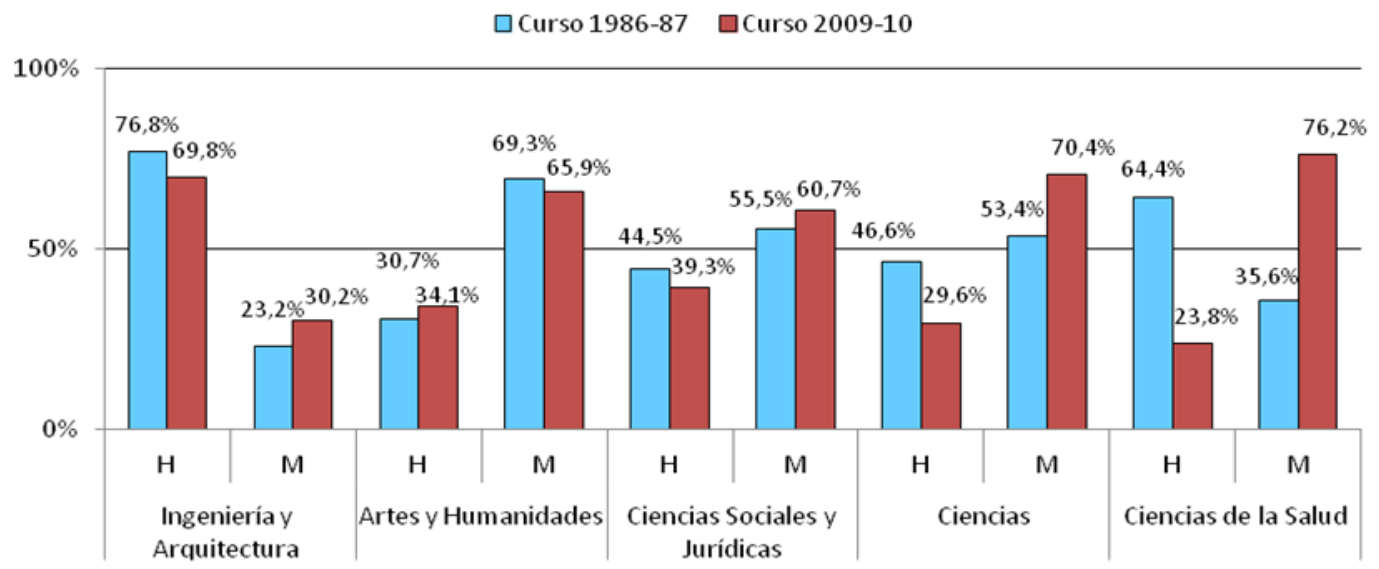

Fuente: Elaboración propia a partir de los Anuarios Estadísticos de Castilla y León, y del INE. Nota: H: Hombres; M: Mujeres. 
Tras las firmas de las Declaraciones de la Sorbona en 1998 y de Bolonia en 1999, dirigidas a homogeneizar los diferentes sistemas universitarios nacionales europeos, el Gobierno de España aprueba la Ley Orgánica de Universidades 6/2011, de 20 de diciembre (LOU) con el fin de dar respuesta al proceso de adaptación al Espacio Europeo de Educación Superior (EEES). Posteriormente, la promulgación de la Ley Orgánica 4/2007, de 12 de abril, de Modificación de la LOU (LOMLOU) contribuye a la armonización del Sistema de Educación Superior español en el marco del EEES a través de la reestructuración de las enseñanzas universitarias oficiales en tres ciclos -Grado, Máster y Doctorado-.

La Universidad de León inicia el proceso de adaptación de las titulaciones al EEES en el curso académico 2009/10, con la implantación de 7 nuevos grados (Grado en: Biología, en Ciencias Ambientales, en Biotecnología, en Historia, en Historia del Arte, en Lengua Española y su Literatura, y en Filología Moderna: Inglés). No obstante, el grueso de las nuevas titulaciones comienza su andadura en el curso 2010/11 con 30 Grados, salvo el Grado en Ingeniería Eléctrica que lo hace en el año académico 2012/13. Actualmente, todas ellos forman un total de 38 titulaciones nuevas, de las que 4 pertenecen a la rama de conocimiento de Artes y Humanidades, 14 a Ciencias sociales y jurídicas, 12 a Ingeniería y Arquitectura, 4 a Ciencias y 4 a Ciencias de la Salud.

El Gráfico 15 muestra el porcentaje de titulaciones por rama de actividad entre los cursos $1986 / 87$ y $2012 / 13$, donde se puede apreciar el incremento que han sufrido las titulaciones pertenecientes a las ramas de Ciencias Sociales y Jurídicas (de un 33\% a un 37\% entre ambos periodos), Ingeniería y Arquitectura (de un $25 \%$ a un $32 \%$ ) y, en menor medida, Ciencias (de un $8 \%$ a un $10,5 \%$ ) en detrimento de las titulaciones asociadas a las ramas de Arte y Humanidades, y Ciencias de la Salud con una disminución de aproximadamente 6 puntos porcentuales, entre ambos periodos.

\section{Gráfico 15}

Distribución porcentual de la oferta de enseñanzas por ramas de conocimiento de la ULE en los cursos 1986/87 y 2012/13

\section{Curso 1986/87}

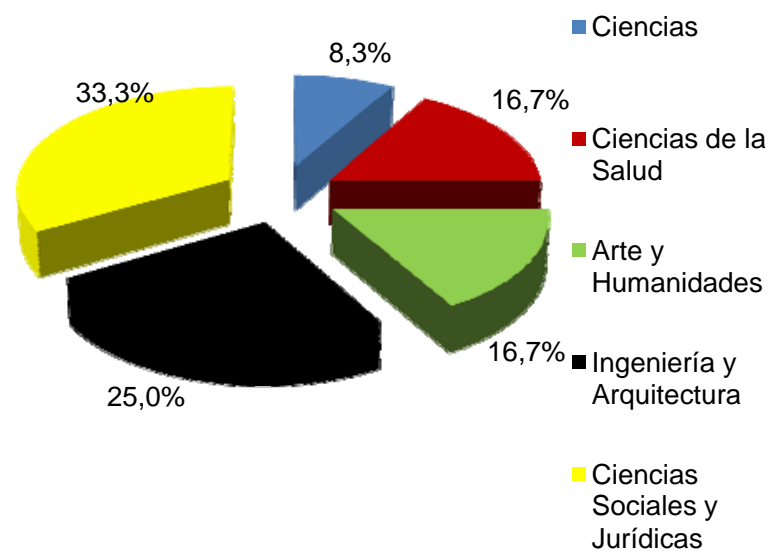

Curso 2012/13

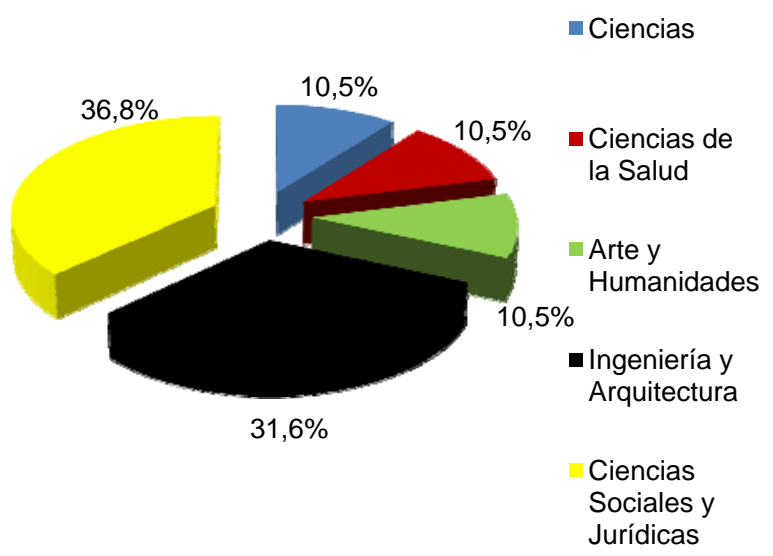

Fuente: Elaboración propia a partir de datos suministrados por la web de ULE (www.unileon.es) y el INE.

Por otra parte, según la web de la Universidad de León, esta institución presenta una oferta de 30 titulaciones oficiales de máster en el curso 2012/13, de los que 4 pertenecen a la rama de conocimiento de Artes y Humanidades, 6 a Cien- cias de la Salud, 13 a Ciencias Sociales y Jurídicas, 10 a Ingeniería y Arquitectura, y 2 a Ciencias. De todos ellos, 6 son másteres interuniversitarios, de los que 2 son de carácter internacional. 


\section{Caractenísticas educativas de la población}

Para determinar el avance de la sociedad desde el punto de vista educativo es preciso considerar variables que informen sobre el nivel de alfabetización de la población. Para ello, los indicadores que se utilizan en este apartado son: la proporción de población de 16 y más años analfabeta/sin estudios, la proporción de población de 16 y más años con estudios superiores y la proporción de población de 25 a 34 años con estudios superiores.

La Tabla 2 recoge el valor de los tres indicadores mencionados anteriormente para los tres ámbitos territoriales (provincial, autonómico y nacional) entre el año 1991 y 2010, según los datos disponibles en la web del INE.

En ella se comprueba que la proporción de población de 16 y más años analfabeta o sin estudios en la provincia de León experimenta un ligero incremento del 1,5\% entre los dos extremos del espacio temporal analizado, con valores del $8,60 \%$ en 1991 y $8,73 \%$ en 2010 , y repunte en 1996 hasta alcanzar el 13,48\%. En relación con otras provincias de España, León pasa de estar en la novena posición en 1991 a la vigésima en 2010 de menor nivel de analfabetismo/sin estudios, lo que significa que ha empeorado su situación. A nivel autonómico y nacional se producen descensos del $20 \%$ y $48 \%$, respectivamente, entre ambos años.

\section{Tabla 2}

Proporción de población de 16 y más años analfabeta/sin estudios, con estudios superiores, y población de 25 a 34 años con estudios superiores a nivel nacional, autonómico y provincial (en \%)

\begin{tabular}{|c|c|c|c|c|c|c|c|c|c|}
\hline \multirow[b]{2}{*}{ Año } & \multicolumn{3}{|c|}{$\begin{array}{l}\text { Proporción de población de } 16 \text { y más } \\
\text { años analfabeta/sin estudios }\end{array}$} & \multicolumn{3}{|c|}{$\begin{array}{l}\text { Proporción de población de } 16 \text { y más } \\
\text { años con estudios superiores }\end{array}$} & \multicolumn{3}{|c|}{$\begin{array}{l}\text { Proporción de población de } 25 \text { a } 34 \\
\text { años con estudios superiores }\end{array}$} \\
\hline & León & CyL & España & León & CyL & España & León & CyL & España \\
\hline 1991 & 8,60 & 9,58 & 20,30 & 10,70 & 11,20 & 10,70 & 24,91 & 23,84 & 21,68 \\
\hline 1992 & 8,20 & 8,90 & 19,80 & 11,40 & 11,60 & 11,20 & 23,79 & 24,65 & 22,22 \\
\hline 1993 & 9,60 & 8,76 & 18,90 & 11,90 & 12,01 & 11,90 & 25,98 & 26,17 & 23,27 \\
\hline 1994 & 12,40 & 9,28 & 18,10 & 12,00 & 12,60 & 12,60 & 26,91 & 27,66 & 24,93 \\
\hline 1995 & 13,00 & 9,24 & 17,60 & 13,40 & 13,61 & 13,50 & 28,50 & 29,40 & 26,33 \\
\hline 1996 & 13,48 & 8,73 & 16,81 & 13,42 & 14,42 & 14,63 & 29,52 & 31,70 & 28,24 \\
\hline 1997 & 11,56 & 8,27 & 16,33 & 13,25 & 15,54 & 15,29 & 27,53 & 34,10 & 29,56 \\
\hline 1998 & 10,03 & 7,96 & 15,59 & 14,93 & 16,27 & 16,04 & 30,60 & 35,51 & 31,18 \\
\hline 1999 & 10,99 & 8,90 & 16,08 & 15,67 & 17,14 & 16,92 & 33,93 & 36,95 & 32,38 \\
\hline 2000 & 10,66 & 8,74 & 16,41 & 14,68 & 17,32 & 17,96 & 36,92 & 38,23 & 33,98 \\
\hline 2001 & 10,09 & 7,83 & 15,43 & 15,72 & 17,49 & 18,64 & 37,81 & 37,74 & 35,43 \\
\hline 2002 & 10,55 & 8,14 & 14,31 & 16,82 & 18,01 & 19,20 & 37,44 & 38,85 & 36,66 \\
\hline 2003 & 4,31 & 5,47 & 12,22 & 16,06 & 19,42 & 19,66 & 36,60 & 41,29 & 37,08 \\
\hline 2004 & 3,79 & 5,13 & 11,75 & 17,41 & 20,08 & 20,47 & 42,26 & 42,98 & 38,13 \\
\hline 2005 & 7,80 & 7,51 & 12,42 & 19,04 & 20,87 & 22,01 & 45,27 & 43,82 & 39,73 \\
\hline 2006 & 7,74 & 7,94 & 11,92 & 17,93 & 21,43 & 22,34 & 38,98 & 42,02 & 39,20 \\
\hline 2007 & 8,64 & 7,93 & 11,65 & 19,81 & 22,01 & 22,81 & 39,71 & 43,15 & 38,93 \\
\hline 2008 & 8,67 & 8,29 & 11,29 & 21,01 & 22,72 & 23,08 & 40,07 & 42,72 & 38,76 \\
\hline 2009 & 9,45 & 8,45 & 11,19 & 20,36 & 23,22 & 23,38 & 36,51 & 41,20 & 38,21 \\
\hline 2010 & 8,73 & 7,69 & 10,60 & 19,91 & 23,78 & 24,28 & 40,39 & 42,89 & 39,12 \\
\hline
\end{tabular}

Fuente: Indicadores sociales - INE. 
En cuanto a la proporción de población de 16 y más años con estudios superiores y de 25 a 34 años con estudios superiores aproximadamente se duplica en los tres ámbitos territoriales entre 1991 y 2010, presentando valores ligeramente inferiores la provincia de León en el último año con respecto a CyL y España.

El análisis por sexo dentro de la provincia de León en los años 1991 y 2010 muestra cómo las muje- res presentan valores superiores en ambos ejercicios tanto en la población de 16 y más años como entre 25 a 34 años con estudios superiores. Sin embargo, el nivel de población de 16 y más años analfabeta/sin estudios es ligeramente superior a los hombres (Gráfico 16). Esto significa que las mujeres realizan estudios superiores en mayor proporción que los hombres y que una parte de aquéllas que no lo hacen, ni siguiera alcanzan los estudios básicos.

\section{Gráfico 16}

Porcentaje de población de 16 y más años analfabeta/sin estudios, con estudios superiores, y población de 25 a 34 años con estudios superiores en la provincia de León y por sexo

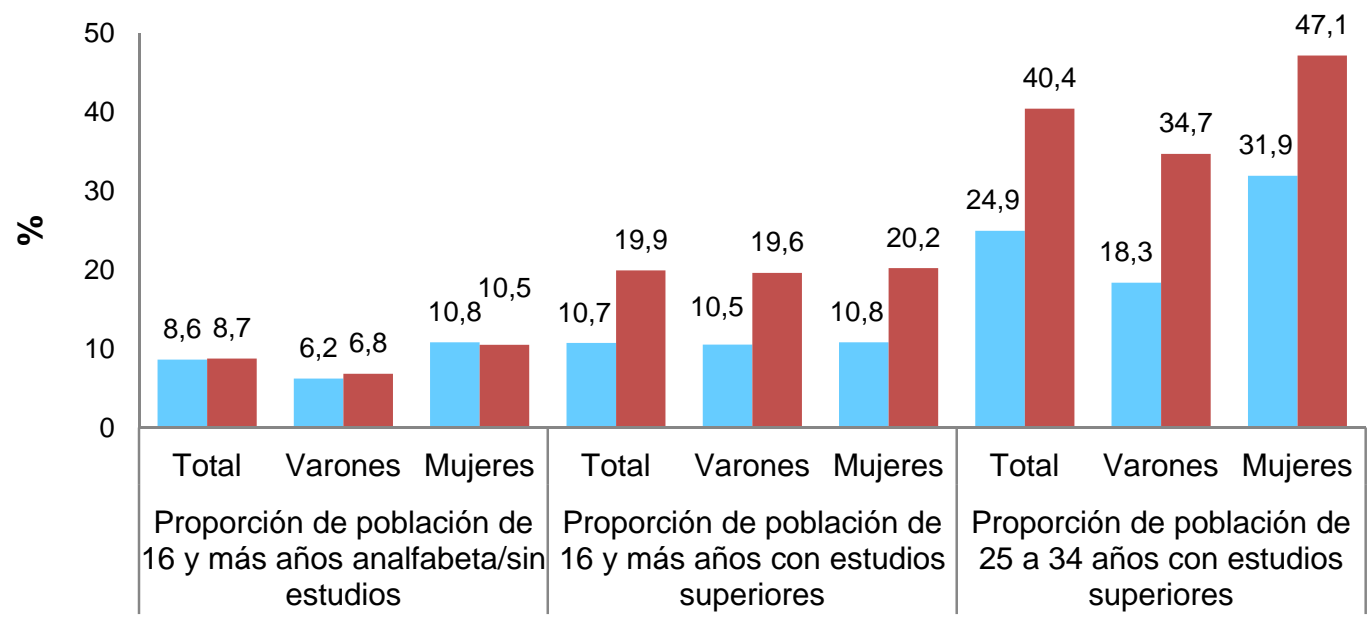

$\square 1991 \square 2010$

Fuente: Elaboración propia a partir de datos del INE.

\section{Conclusiones}

En los últimos 25 años el sistema educativo en la provincia de León se ha visto afectado por las distintas disposiciones legales que se han aprobado en esta materia, obligando a una reestructuración tanto de las enseñanzas universitarias como no universitarias.

Del mismo modo, la disminución de la natalidad y el envejecimiento de la población en la provincia de León a lo largo del tiempo también han influido en el descenso de algunas de las variables analizadas, tales como el número de estudiantes matriculados, la disminución de los fondos públicos destinados a la educación, el número de centros escolares, el número de unidades/ grupos docentes, entre otras.

En la provincia de León, al igual que ocurre en el resto de España, las políticas económicas en materia de educación no superior han ido dirigidas a mejorar la eficiencia de los recursos públicos destinados a educación, atendiendo al mayor número de estudiantes posible a través de la concentración de los centros escolares en las ciudades más pobladas del territorio.

El aumento del número de becas, becarios y cuantía en euros destinada a ayudas al estudio en CyL contribuyen a eliminar el obstáculo de las diferencias económicas para acceder a la educación en condiciones de igualdad, sobre todo 
en enseñanzas no universitarias. No obstante, esta Comunidad Autónoma todavía tiene mucho camino por recorrer para alcanzar la media nacional.

La enseñanza universitaria en León está mejor posicionada. El incremento de la oferta de titulaciones universitarias, algunas de ellas no impartidas en universidades periféricas, motiva a que estudiantes de otras provincias elijan la Universidad de León como destino en sus estudios superiores, teniendo un efecto positivo sobre el número de alumnos matriculados en dicha institución.

Por otra parte, el inicio de la adaptación del Espacio Europeo de Educación Superior en la Universidad de León en el curso 2009/10 ocasiona la sustitución de las antiguas Licenciaturas y Diplomaturas por los nuevos títulos de Grado, hoy en día totalmente implantados. También, el EEES ha dado lugar a la proliferación de másteres oficiales, algunos de ellos de carácter internacional impartidos en colaboración con otras Instituciones de Educación Superior de otros países europeos, contribuyendo a la internacionalización de la ULE.

La creación y desarrollo de la Universidad de León ha sido fundamental para mejorar el nivel educativo de la población en la provincia de León, duplicando el número de personas de más de 16 años con estudios superiores entre 1991 y 2010. Esto enriquece a la provincia tanto en capital intelectual como económico, aunque la casi ausencia de industria, junto con la escasez de oportunidades de trabajo en la provincia, obligan a muchos de estos estudiantes a emigrar a otras regiones o incluso a otros países.

Transcurridos varios años desde el comienzo de la crisis en 2008, la ULE, así como otras universidades españolas, notan los efectos negativos derivados de esa situación. En primer lugar, la reducción de fondos públicos procedentes de las Administraciones Públicas, así como de fondos propios derivados de las tasas y otras fuentes, producen una disminución de la financiación en estas instituciones, debiendo ajustarse lo mejor posible para sobrevivir. En segundo lugar, la caída de estudiantes por la imposibilidad de costearse sus estudios, bien por la pérdida de la beca o por la posición económica precaria en la que se encuentran sus familiares.

Las estrategias de desarrollo en materia de educación no universitaria en la provincia de León dependen principalmente de decisiones políticas impuestas por la Comunidad Autónoma o el Estado, por lo que la provincia poco puede hacer en este sentido, simplemente luchar por lo que crea razonablemente que es mejor para el territorio. En cuento a enseñanza universitaria, la ULE debe intensificar sus esfuerzos para hacer atractivas, tanto a nivel regional como nacional, las titulaciones que están implantadas, así como para establecer nuevas titulaciones, ya sean de grado o máster, que ayuden al desarrollo intelectual y económico, no sólo de la provincia, sino también de la nación.

\section{Referencias}

Instituto Nacional de Estadística (INE) (1996-2005). Educación. Recuperado en marzo de 2013 de http://www.ine.es/.

Instituto Nacional de Estadística (INE) (2011). Indicadores sociales. Recuperado en marzo de 2013 de http://www.ine.es/.

Junta de Castilla y León (1987-2002). Anuarios Estadísticos de Castilla y León. Consejería de Economía y Hacienda.

Junta de Castilla y León (2002-2012). Estadística de la Enseñanza no Universitaria. Portal de Educación. http://www.educa.jcyl.es/es/ [fecha de consulta: abril 2013].

Ministerio de Educación, Cultura y Deporte (1990-2011). Educación. Recuperado en marzo de 2013 de http://www.mecd.gob.es/portada-mecd/.

Red Europea de Información sobre Educación (EURYDICE) (2011). Resumen descriptivo de los sistemas educativos europeos. Ministerio de Educación, Cultura y Deporte. Recuperado en marzo de 2013 de http://www.mecd.gob.es/portada-mecd/. 